\title{
Yağmur Hendeklerinin Kapasite ve Maliyet Hesapları
}

\author{
Uğur ÜNAL ${ }^{1}$, Dilek Eren AKYÜZ ${ }^{1 *}$ \\ ${ }^{1}$ İstanbul Üniversitesi, Mühendislik Fakültesi, İnşaat Müh. Bölümü, İstanbul, Türkiye
}

"Sorumlu Yazar: dilek.akyuz@ istanbul.edu.tr

Geliş Tarihi: 29.06 .2017

Kabul Tarihi: 24.11.2017

\section{Özet}

Suya duyarlı şehirlerde kullanılan yeşil altyapı sistemleri; şehirleşmenin ve nüfus artışının olumsuz etkilerini azaltmak, yağıştan daha fazla yararlanmak için inşa edilirler. Bu sistemlerden biri olan yağmur hendekleri; yağıştan maksimum şekilde faydalanmak, yağmur suyunu arıtmak ve sızmayı arttırmak için tercih edilirler. Bu çalışmada; yağmur hendeklerinin sürdürülebilirliğe sağladığı katkılardan dolayı ülkemizdeki kullanımlarının yaygınlaştırılması ve yeni yönetmeliğin değerlendirilmesi amaçlanmıştır. $\mathrm{Bu}$ sebeple yağmur hendeklerinin kapasite hesapları, tasarım parametreleri, yağmur hendeklerinin inşaat ve bakım maliyetleri detaylı bir şekilde açıklanarak İstanbul ili Göztepe bölgesi için yağmur hendeği kapasite hesabı yapılmıştır. Yapılan hesaplarda uluslararası literatürde ve 23 Haziran 2017 tarihinde yayınlanan yağmur suyu toplama, depolama ve deşarj sistemleri hakkında yönetmelikte belirtilen yöntemler kullanılarak sonuçlar kıyaslanmıştır. Bu yönetmelik çoğunlukla geleneksel sistemlere (borulu altyapı sistemleri ve beton kanallar gibi) yönelik olarak hazırlanmış, yağmur hendekleri gibi sürdürülebilir sistemlere yeterince yer verilmemiştir. Böylece bu çalışmada yönetmelikte bulunmayan hesaplar ve tasarım kriterleri detaylı şekilde açıklanarak sürdürülebilir sistemlerin yaygınlaştırılmasına katkı sağlanmıştır.

Anahtar Kelimeler: Yağmur hendeği, Kapasite hesabı, Maliyet hesabı, Tasarım parametreleri.

\section{Capacity and Cost Calculations of Swales}

\begin{abstract}
Green infrastructures used in water-sensitive cities; they are built to reduce the adverse effects of urbanization and population growth and to get more gain from precipitation. one of these systems; swale are prefer to use with aim of maximizing obtained gain from precipitation, treating precipitation and increasing infiltration. In this study; it is aimed to wide spread of using swale in our country becuase of its contribute to sustainability and to evaluate the new regulation. For this reason, capacity calculations of swales, design parameters, construction and maintance costs of swale are explained in detail and swale capacity calculation for the Göztepe district of Istanbul province is made. The results are compared by using the methods specified in the regulation on rainwater collection, storage and discharge systems published on June 23, 2017 and in the international literature. This regulation has not been adequately addressed by sustainable systems such as swales, and it generally prepared for traditional systems (such as pipeline infrastructure systems and concrete conduits). Thus, in this study, calculations and design criterias, that are not included in the regulation, are explained in detail and contributed to spreading of sustainable systems.
\end{abstract}

Keywords: Swale, Capacity calculation, Cost calculation, Design parameters. 


\section{Giriş}

\subsection{Konunun Anlam ve Önemi}

Ülkeler kişi başına düşen kullanılabilir su miktarlarına göre sınıflandırılmaktadır. Kullanılabilir su miktarı; $10.000 \mathrm{~m}^{3}$ 'ten fazla olan ülkeler su zengini, $2.000 \mathrm{~m}^{3}$ 'ten ve $1.000 \mathrm{~m}^{3}$ 'ten az suya sahip olan ülkeler ise sırasıyla su azlığı çeken ve su fakiri ülkeler olarak adlandırılır. Ülkemizde ise 2010 nüfus sayımına göre 73,72 milyon için kişi başına düşen kullanılabilir su miktarı $1519 \mathrm{~m}^{3}$ civarındadır ve ülkemiz su azlığı çeken bir ülke konumundadır (URL-1). TUİK tarafından yapılan araştırmalara göre; 2030 yılında nüfusumuzun 100 milyon olacağı göz önüne alındığında; kişi başına düşen su miktarı daha da azalacak ve $1120 \mathrm{~m}^{3}$ olacaktır (URL-1). Bu da ülkemizdeki su kaynaklarının yönetimine hayati derecede önem verilmesi gerektiğini göstermektedir. İklim değişikliğinin etkisi de düşünüldüğünde ülkemizde kişi başına düşen kullanılabilir su miktarının ciddi oranda azalması beklenmektedir. $\mathrm{Bu}$ nedenle altyapı ve yönetimsel düzenlemeler yapılmalı ve gerekli önlemler alınmalıdır.

Nüfus miktarındaki artışa paralel olarak şehirleşme oranı da artmaktadır. Bunun sonucu olarak havza alanındaki geçirimsizlik yüzdesinin artmasıyla yağış daha fazla yüzeysel akışa geçmektedir. Kısaca; yağış yeraltına sızamamakta ve yeraltısu seviyesi azalmaktadır. Ayrıca yüzeysel akış miktarındaki artış sebebi ile kentsel alanlarda meydana gelen sel ve taşkın olaylarının sıklı̆̆ı ve şiddeti artmaktadır (URL-2). Şekil 1'de şehirleşme öncesi ve sonrası hidrolojik çevrimin elemanlarında; buharlaşma, yüzeysel akış ve sızma miktarlarında meydana gelen değişim verilmiştir. Bütün bu birbirini tetikleyen olaylar, suyun doğadaki hidrolojik çevrimini daha kısa sürede tamamlamasına ve bu da su kalitesinin giderek azalmasına neden olmaktadır.

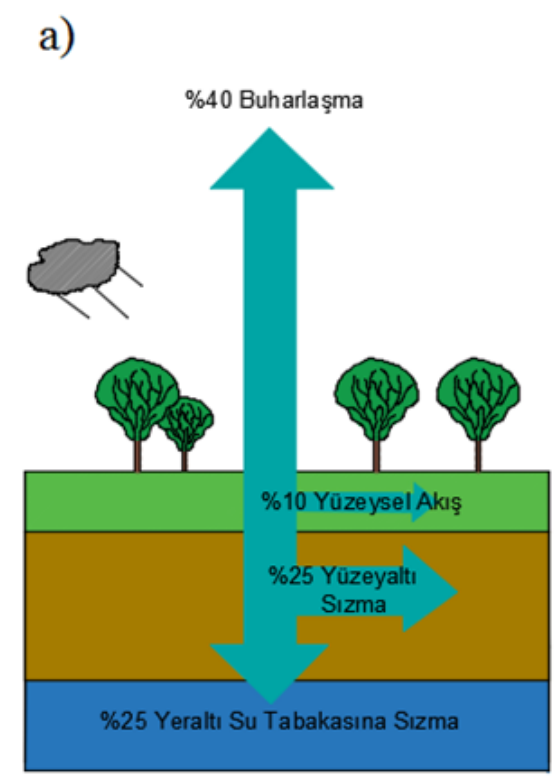

b)

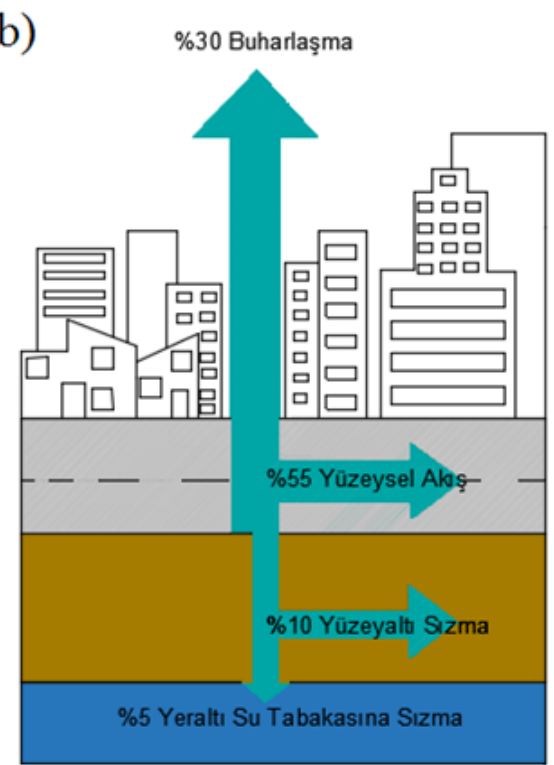

Şekil 1. a) Şehirleşme öncesi b) Şehirleşme sonrası hidrolojik döngü (URL-2). 
$\mathrm{Bu}$ sorunların üstesinden gelebilmek için su kaynaklarımızı doğru ve akıllıca kullanmamız gerekmektedir. Bu ise; optimum sürdürülebilir yönetim anlayışı ile mümkün olmaktadır (Rahman ve Weber, 2003). Sürdürülebilir yönetim uygulamalarından biri olan yağmur hendekleri, yağmur suyundan daha fazla yararlanmak amacıyla inşa edilen diğer yağmur suyu yönetim uygulamalarına göre daha ekonomik ve uygulaması kolay olan bir yöntemdir (ARC, 1992; BMP Minnesota, 2001a; BMP Minnesota, 2001b; BMP California, 2003; WSUD, 2006; WSUD, 2010). Bu nedenle yurtdışında yaygın şekilde kullanılması tavsiye edilmektedir (CWP, 1998; Hengen ve diğ., 2016).

Yağmur hendeklerinin ekonomik olmalarının yanında; yağmursuyunu taşıması, hendek içinde biriktirerek yeraltına sızdırması, böylece yeraltısuyunun beslenmesine katkı sağlaması, su kalitesini arttırması, tarımda sulama suyuna olan ihtiyacı azaltması, erozyonu önlemesi, yol kaplamasındaki yağmur suyunu toplayarak sürüş güvenliğini sağlaması, biyolojik çeşitliliği arttırması, yerleşim bölgeleri için estetik bir görünüş olması gibi farklı birçok faydası bulunmaktadır (ARC, 1992; BMP Minnesota, 2001a; BMP Minnesota, 2001b; BMP California, 2003; WSUD, 2006; WSUD, 2010; Revitt ve diğ., 2017).

$\mathrm{Bu}$ hendeklerin kullanım yerleri, yüzeylerinin sslak veya kuru olması durumuna göre değişmektedir. Islak yağmur hendekleri; kırsal bölgelere, yerleşim yerlerinin dışına yapılırken; kuru yağmur hendekleri; yerleşim bölgelerine, alışveriş merkezlerine, okul bahçelerine, yol kenarlarına, orta refüje, endüstri ve ticari alanlara yapılmaktadır (BMP Minnesota, 2001b; WSUD, 2010; Flanagan ve di.̆., 2017).

Yağmur hendekleri bu faydalarından ve kullanım yerlerinin çok çeşitli olmasından dolayı dünyada yaygın şekilde uygulanmaktadır. Ülkemizde ise daha çok permakültür çiftliklerinde tarımsal su hasadı amacıyla kısıtlı şekilde inşa edilmektedir. Ülkemizde bu hendeklerin kısıtlı uygulama alanları Marmariç, Belentepe ve Kızıltepe permakültür çiftlikleri ile Tahtacıörencik ve Bostancık köyleridir (URL-3).

Hazırlanan bu çalışma ile, yağmur hendeklerinin kapasite ve maliyet hesapları anlatılmaktadır. Kapasite hesapları için hem uluslararası literatür hem de ülkemizde 23 Haziran 2017 tarihinde 30105 sayı ile Resmi Gazetede yayınlanarak yürürlüğe giren yağmur suyu toplama, depolama ve deşarj sistemleri yönetmeliği esas alınmıştır. Literatür ve 30105 sayılı yönetmeliğe göre örnek bir yağmur hendeği kapasite hesabı detaylı olarak yapılarak bu iki hesap yönteminin karşılaştırılması yapılmış ve yeni yönetmeliğin sürdürülebilirlik açısından değerlendirilmiştir. Bu çalışma ile yağmur hendeklerinin ülkemizdeki kullanımlarının yaygınlaştırılması ve hesap yöntemlerine katkı sağlanması hedeflenmektedir. 


\subsubsection{Sayılı Yönetmelik}

Çevre ve Şehircilik Bakanlığı tarafından 23 Haziran 2017 tarih ve 30105 sayılı ile Resmi Gazete'de yayınlanan Yağmursuyu Toplama, Depolama ve Deşarj Sistemleri Hakkında Yönetmelik yürürlüğe girmiştir. Bu yönetmeliğin amacı Madde 1'de; ... yağmursuyu toplama, depolama ve deşarj sistemlerinin planlanmasına, tasarımına, projelendirilmesine, yapımına ve işletilmesine ilişkin usul ve esasları düzenlemektir. ve kapsamı ise Madde 2'de; ... halk să̆liğını ve güvenliğini, çevrenin korunmasını, sistemin sürdürülebilir olmasını, içmesuyu kaynaklarının suyla taşınan kirliliklerden korunmasını esas alarak yağmursuyu toplama, depolama ve deşarj sistemlerinin planlanmasına, tasarımına, projelendirilmesine, yapımına ve işletilmesine ilişkin usul ve esasları kapsar. ifadeleri ile verilmektedir.

$\mathrm{Bu}$ yönetmelik daha çok geleneksel yağmur suyu yönetim sistemlerinin (borulu sistemler) planlama, tasarım ve projelendirmesine yönelik olarak hazırlanmıştır. Şehirleşme oranı yüksek olan bölgelerde yüzeysel akış miktarını ve hızını azaltmak amacıyla yağmursuyu depolama ve geciktirme yapıları ile sürdürülebilir sistemlere ise kısıtlı şekilde (Maddeler 15 ve 16) yer vermektedir. Oysa güncel bir yönetmelikte yeşil altyapı olarak da adlandırılan sürdürülebilir sistemlere (yağmur hendekleri, gözenekli kaplamalar, sızdırma hendekleri, yağmur bahçeleri, yeşil çatılar vb.) daha detaylı şekilde yer verilerek bu sistemlerin kullanımının şiddetle tavsiye edilmesi gerekir. Ayrıca bu yönetmelik sürdürülebilir sistemlerin hesap yöntemlerine de yeterince yer verilmemektedir. Bu çalışma ile hem yağmur hendeklerinin tanıtımı hem de bu hendeklere ait kapasite ve maliyet hesapları detaylı şekilde açıklanarak yönetmeliğe katkı sağlanması amaçlanmıştır.

\section{Materyal ve Metot}

$\mathrm{Bu}$ bölümde yağmur hendeklerinin kapasite ve maliyet hesapları ile tasarım parametreleri anlatılmaktadır. Yağmur hendeklerine ait kapasite hesapları hem uluslararası literatüre hem de ülkemizde 30105 sayı ile Resmi Gazetede yayınlanarak yürürlüğe giren yağmur suyu toplama, depolama ve deşarj sistemleri yönetmeliğine uygun olarak açıklanmaktadır.

\subsection{Yağmur Hendeklerinin Kapasite Hesapları}

\subsubsection{Uluslararası Literatüre Göre Kapasite Hesapları}

Yağmur hendeklerinin taşıma kapasitelerinin hesaplanmasında; Rasyonel metot, Manning denklemi, serbest akım koşulları için savak denklemi ve batmış durumdaki çıkış akımları için orifis 
denklemi kullanılmaktadır. Hesap adımlarını oluşturan bu metotlar ve denklemler aşağıda detaylı olarak açıklanmaktadır.

\subsubsection{Rasyonel Metot}

Yağmur hendekleri genellikle 2 ile 4 hektarlık küçük alanlı bölgeleri arıtmak için inşa edilmektedir (Yao, 2013). Bu sebeple küçük alanlarda akış debisini doğrulukla veren rasyonel metot, (Denklem 1) hendeklere ulaşan pik debilerin hesaplanmasında rahatlıkla kullanılabilir. Rasyonel metodun hesaplanmasında gerekli olan yağışın geçiş süresi $\left(t_{c}\right)$; hendek boyu uzunluğunun 50 metreden fazla olması durumunda tabaka ve kanal akımlarına ait geçiş $\left(t_{\text {tabaka }}+t_{\text {kanal }}\right)$ sürelerinin toplamından oluşmaktadır. Hendek boyu uzunluğunun 50 metreden az olduğu durumlarda ise kanal akımımın geçiş süresi $\left(t_{\text {kanal }}\right)$ sıfır olarak kabul edilip toplam geçiş süresi $\left(t_{c}\right)$ tabaka süresine $\left(t_{\text {tabaka }}\right)$ eşit alınmaktadır. Denklem 2'de görülen Horton katsayısı $(n *)$ Tablo 1'den okunarak hesaplanır. Bu denklemde bulunan yağış şiddeti $(I)$ ve tabaka süresi $\left(t_{\text {tabaka }}\right)$ arasında; yağış şiddetisüre-tekerrür eğrilerine göre bu iki değer birbirleriyle eşleşinceye kadar iterasyon yapılır. Bulunan değer tabaka süresine $\left(t_{\text {tabaka }}\right)$ eşittir. Daha sonra toplam geçiş süresine $\left(t_{c}\right)$ bağlı olarak yağış şiddeti-süre-tekerrür eğrilerinden y yıllık yağış şiddeti $\left(I_{y}\right)$ okunur. Denklem 1'deki $C_{y}$ terimi; y yıllık tekrarlanma sıklığına sahip yüzeysel akış katsayısının değerini göstermektedir. 10 yıllık tekrarlanma sıklığına sahip yüzeysel akış katsayısı $\left(\mathrm{C}_{10}\right)$ Tablo 2'deki geçirimsizlik oranına göre Tablo 3 ve 4 'te verilmektedir. Farklı değerlere ait $\mathrm{C}_{\mathrm{y}}$ değerleri ise $\left(\mathrm{C}_{50}\right.$ ve $\left.\mathrm{C}_{100}\right)$ Tablo 5 'te verilen frekans faktörüne bağlı olarak Denklem 4 ile hesaplanabilir.

$$
Q_{y}=\left(C_{y} * I_{y} * A\right) / 360
$$

Burada; Qy: Hendekte oluşan y yıllık pik debisiyi $\left(\mathrm{m}^{3} / \mathrm{s}\right), C_{y}$ : y yıllık yüzeysel akış katsayısını, $I_{y}:$ y yıllık yağış şiddetini (mm/sa), ve $A$ : Havza alanını (ha) ifade etmektedir.

$$
t_{\text {tabaka }}=6.94 * \frac{\left(L_{t} * n^{*}\right)^{0.6}}{I^{0.4} * S^{0.3}}
$$

Burada; $t_{\text {tabaka }}$ : tabaka akımının geçiş süresini $(\mathrm{dk}), L_{t}$ : tabaka akımı uzunluğunu $(\mathrm{m}), n^{*}$ : Horton pürüzlülük katsayısını, $I$ : yağış şiddetini $(\mathrm{mm} / \mathrm{sa})$ ve $S$ : boyuna eğimi ifade etmektedir.

$$
t_{\text {kanal }}=L_{k} /\left(60 * V_{\text {ort }}\right)
$$


Burada; $t_{\text {kanal }}$ : kanal akımının geçiş süresini $(\mathrm{dk}), L_{k}$ : kanal akımı uzunluğunu $(\mathrm{m})$ ve $V_{\text {ort }}$ : ortalama akım hızını $\left(\mathrm{m}^{3} / \mathrm{s}\right)$ ifade etmektedir.

Yüzeysel akış katsayısı $\left(\mathrm{C}_{\mathrm{y}}\right)$ ve pik debinin $\left(\mathrm{Q}_{\mathrm{pik}}\right)$ hesaplanması için gerekli olan adımlar aşağıda maddeler halinde özetlenmektedir.

i. Boyuna eğimi (S), toplam akım yolu uzunluğu $\left(L_{T}\right)$ ve havza alanı (A) projeye göre hesaplanır ve uygunluk kriterlerine göre değerlendirilir,

ii. Denklem 2'de kullanılan Horton pürüzlülük katsayısı ( $\left.n^{*}\right)$ Tablo 1'den okunarak belirlenir,

iii. Denklem 2'de tüm bilinenler yerine konularak yağış şiddeti ile tabaka akımının geçiş süresi arasında yağış şiddeti-süre tekerrür eğrilerine göre iterasyon yapılarak tabaka akımının geçiş süresi bulunur. Eğer toplam akım yolu uzunluğu 50 metreden fazla ise Denklem 3 ile kanal akımına ait geçiş süresi de hesaplanır,

iv. Tabaka akımı ile kanal akımının geçiş süresi toplanarak toplam geçiş süresi ( $t_{c}$ ) elde edilir. Bu süreye göre yağış şiddeti-süre tekerrür eğrilerinden y yıllık yağış şiddeti (I10 ve I100 gibi) belirlenir,

v. Yağmur hendeğinin inşa edileceği bölgeye göre geçirimsizlik oranı $\left(f_{i}\right)$ Tablo 2'den okunur,

vi. 10 yıllık tekrarlanma sıklığına sahip 1 saatlik yağış şiddetine $\left({ }^{1} \mathrm{I}_{10}\right)$ ve geçirimsizlik oranına $\left(f_{i}\right)$ bağlı olarak Tablo 3 (geçirimsizlik oranı sıfırdan farklı ise) veya 4'ten (geçirimsizlik oranı sıfıra eşit ise) 10 yıllık tekrarlanma sıklığına sahip yüzeysel akış katsayısının $\left(\mathrm{C}_{10}\right)$ değeri belirlenir,

vii. Farklı tekrarlanma sıklığına sahip yüzeysel akış katsayılarının $\left(\mathrm{C}_{2}, \mathrm{C}_{50}, \mathrm{C}_{100}\right.$ gibi $)$ bulunabilmesi için ise Tablo 5'te verilen frekans faktörleri Denklem 4'te yerine konularak gerekli çarpımlar yapılır. Denklem 4 ile hesaplanan $C_{y}$ değeri kentsel bölgeler için 1'den büyük çıkarsa, bu değer 1'e eşit kabul edilir,

viii. Elde edilen y yıllık yüzeysel akış katsayısı $\left(\mathrm{C}_{\mathrm{y}}\right)$, y yıllık yağış şiddeti ( $\left.\mathrm{I}_{\mathrm{y}}\right)$ ve havza alanı (A) Denklem 1'de yerine konularak pik debi hesaplanır,

$$
C_{y}=F_{y} * C_{10}
$$

Burada; $C_{y}$ : y yıllık yüzeysel akış katsayısını, $F_{y}$ : y yıllık frekans faktörünü ve $C_{10}: 10$ yıllık yüzeysel akış katsayısını ifade etmektedir. 
Tablo 1. Horton yüzey pürüzlülük katsayısı ( $n *$; QUDM, 2007).

\begin{tabular}{lc}
\hline Yüzey Tipi & Horton Pürüzlülük Katsayısı (n*) \\
\hline Beton veya Asfalt & $0.010-0.013$ \\
Sade Kum & $0.010-0.016$ \\
Çakıllı Yüzey & $0.012-0.030$ \\
Killi Kumlu Zemin (Aşınmış) & $0.012-0.033$ \\
Seyrek Bitki Örtüsü & $0.053-0.130$ \\
Kisa Çimler, Otlak & $0.100-0.200$ \\
Çimler & $0.170-0.480$ \\
\hline
\end{tabular}

Tablo 2. Bölgelere göre geçirimsizlik oranları ( $f_{i}$; QUDM, 2007; SMR Coolangatta, 2008).

\begin{tabular}{lc}
\hline \multicolumn{1}{c}{ Kategori } & Geçirimsizlik oranı $\left(\boldsymbol{f}_{\boldsymbol{i}}\right)$ \\
\hline İş Merkezleri & 1.00 \\
Ticari, Yerel İşletmeler, Komşu Tesisler, Hizmet Sektörü, Genel Sanayi, Ev Endüstrisi & 0.90 \\
Yollar, Otoparklar gibi Önemli Kaplama Alanları & 0.90 \\
*Kentsel Yerleşim - Yüksek Yoğunluklu & $0.70-0.90$ \\
Kentsel Yerleşim - Düşük Yoğunluklu (Yollar dahil) & $0.45-0.85$ \\
Kentsel Yerleşim - Düşük Yoğunluklu (Yollar hariç) & $0.40-0.75$ \\
Kırsal Yerleşim & $0.10-0.20$ \\
Açık alanlar, Parklar vb. & 0.00 \\
\hline *Bitşşik nizam evler için $f_{i:}: 0.7$, bir hektarda 20 konuttan fazla olan bölgeler için $f_{i:}: 0.85$, çok katlı evler için $f_{i:} 0.9$
\end{tabular}

Tablo 3. 10 yıllık ortalama tekrarlanma sıklığına sahip yüzeysel akış katsayısı ( $C_{10}$; QUDM, 2007).

\begin{tabular}{c|ccccccc}
\hline \multirow{2}{*}{$\begin{array}{c}\text { Yağıs̆ Şiddeti } \\
(\mathbf{m m} / \mathbf{s a})^{\mathbf{1}} \mathbf{I}_{\mathbf{1 0}}\end{array}$} & $\mathbf{0 . 0 0}$ & $\mathbf{0 . 2 0}$ & $\mathbf{0 . 4 0}$ & $\mathbf{0 . 6 0}$ & $\mathbf{0 . 8 0}$ & $\mathbf{0 . 9 0}$ & $\mathbf{1 . 0 0}$ \\
\cline { 2 - 8 } & & 0.44 & 0.55 & 0.67 & 0.78 & 0.84 & 0.90 \\
$\mathbf{3 9 - 4 4}$ & & 0.49 & 0.60 & 0.70 & 0.80 & 0.85 & 0.90 \\
$\mathbf{4 5 - 4 9}$ & & 0.55 & 0.64 & 0.72 & 0.81 & 0.86 & 0.90 \\
$\mathbf{5 0 - 5 4}$ & Tablo 4'e & 0.60 & 0.68 & 0.75 & 0.83 & 0.86 & 0.90 \\
$\mathbf{5 5 - 5 9}$ & Bakınız. & 0.65 & 0.72 & 0.78 & 0.84 & 0.87 & 0.90 \\
$\mathbf{6 0 - 6 4}$ & & 0.71 & 0.76 & 0.80 & 0.85 & 0.88 & 0.90 \\
$\mathbf{6 5 - 6 9}$ & & 0.74 & 0.78 & 0.82 & 0.86 & 0.88 & 0.90 \\
$\mathbf{7 0 - 9 0}$ & & &
\end{tabular}

${ }^{1} \mathrm{I}_{10}$ : 10 yıllık tekrarlanma sıklığına sahip 1 saatlik yağış şiddeti $(\mathrm{mm} / \mathrm{sa}), \mathrm{C}_{10}: 10$ yıllık tekrarlanma sıklığına sahip yüzeysel akış katsayısı, $f_{i}$ : Geçirimsizlik oranı.

Tablo 4. Geçirimsizlik oranı sıfır olan yüzeysel akış katsayısı değerleri (QUDM, 2007).

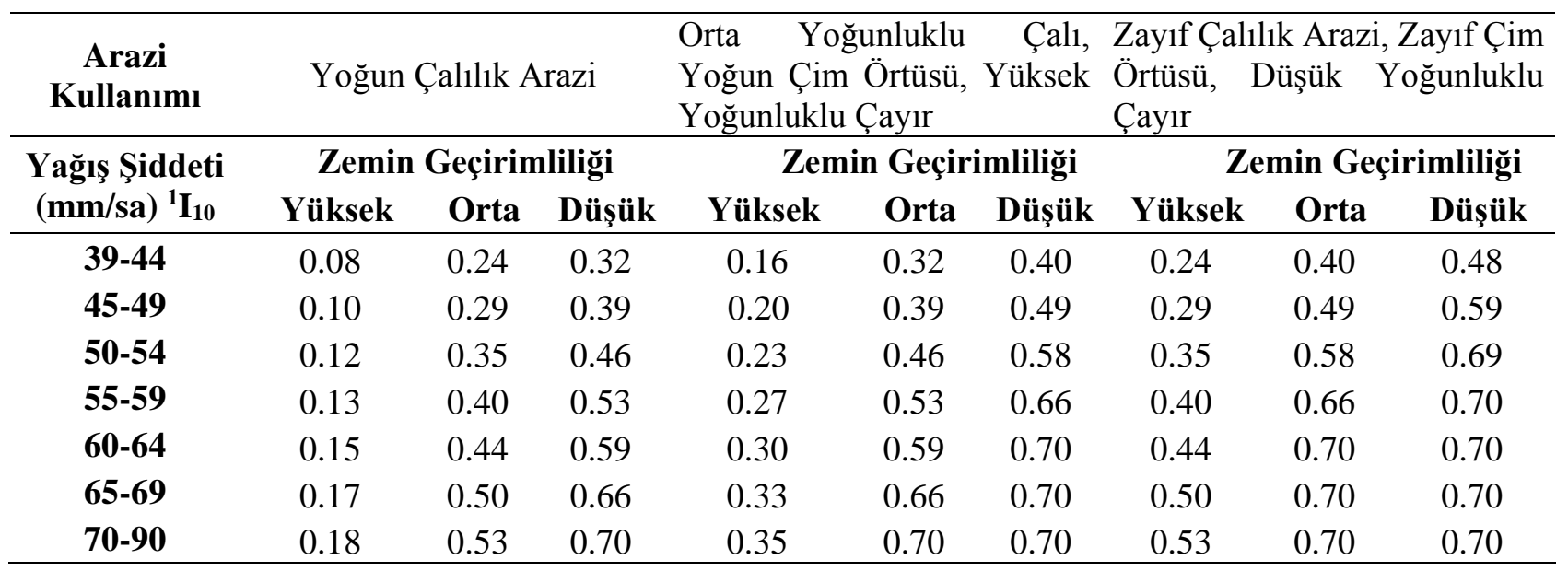


Tablo 5. Tekrarlanma sıklığına bağlı frekans faktörü (Fy; QUDM, 2007; SMR Coolangatta, 2008).

\begin{tabular}{cc}
\hline Ortalama Tekrarlanma Sıklığ & Frekans Faktörü $\left(\mathbf{F}_{\mathbf{y}}\right)$ \\
\hline 1 & 0.80 \\
2 & 0.85 \\
5 & 0.95 \\
10 & 1.00 \\
20 & 1.05 \\
50 & 1.15 \\
100 & 1.20 \\
\hline
\end{tabular}

\subsubsection{Manning Denklemi}

Yağmur hendeklerinde oluşacak ortalama hızın hesabı için Manning denklemi kullanılmaktadır. Denklem 5 ile bulunan ortalama hız, süreklilik denklemine göre hendek en kesit alanı ile çarpılarak hendeğin kapasitesi hesaplanır.

$$
V_{\text {ort }}=\frac{1}{n} * R_{h}^{2 / 3} * S^{1 / 2}
$$

Burada; $V_{\text {ort }}$ : Yağmur hendeğinde oluşacak ortalama hızı $(\mathrm{m} / \mathrm{s}), n$ : Manning pürüzlülük katsayısını, $R_{h}$ : Hidrolik yarıçapı $(\mathrm{m})$ ve $S$ : Boyuna eğimi ifade eder.

Manning denkleminde bulunan pürüzlülük katsayısı $(n)$ hendeğin kaplandığı malzemeye bağlı olarak değişmektedir. Hendek yüzeyinin bitki örtüsüyle kaplandı̆̆ı durumlar için Manning katsayısı Tablo 6'da, taşla kaplandığı durumlar için Manning katsayısı Tablo 7'de verilmektedir. Ayrıca Denklem 5'te bulunan hidrolik yarıçap değerlerinin hendek en kesit tipine göre hesap yöntemleri EK 1 'de ifade edilmektedir.

Tablo 6. Bitki örtüsüyle kaplı yağmur hendekleri için Manning pürüzlülük katsayısı ( $n$; QUDM, 2007).

\begin{tabular}{c|cccccc}
\hline \multirow{2}{*}{ Hidrolik Yarıçap $\left(\mathbf{R}_{\mathbf{h}}\right)$} & \multicolumn{7}{|c}{ Yağmur Hendeğinin Ĕ̆imi (\%) } \\
\cline { 2 - 7 } & $\mathbf{0 . 1}$ & $\mathbf{0 . 2}$ & $\mathbf{0 . 5}$ & $\mathbf{1 . 0}$ & $\mathbf{2 . 0}$ & $\mathbf{5 . 0}$ \\
\hline $\mathbf{0 . 1}$ & - & - & - & 0.105 & 0.081 & 0.046 \\
$\mathbf{0 . 2}$ & - & 0.091 & 0.068 & 0.057 & 0.043 & 0.030 \\
$\mathbf{0 . 3}$ & 0.078 & 0.064 & 0.053 & 0.043 & 0.031 & 0.030 \\
$\mathbf{0 . 4}$ & 0.063 & 0.054 & 0.044 & 0.033 & 0.030 & 0.030 \\
$\mathbf{0 . 5}$ & 0.056 & 0.050 & 0.038 & 0.030 & 0.030 & 0.030 \\
$\mathbf{0 . 6}$ & 0.051 & 0.047 & 0.034 & 0.030 & 0.030 & 0.030 \\
$\mathbf{0 . 8}$ & 0.047 & 0.044 & 0.030 & 0.030 & 0.030 & 0.030 \\
$\mathbf{1 . 0}$ & 0.044 & 0.044 & 0.030 & 0.030 & 0.030 & 0.030 \\
$>\mathbf{1 . 2}$ & 0.030 & 0.030 & 0.030 & 0.030 & 0.030 & 0.030 \\
\hline
\end{tabular}


Tablo 7. Taşla kaplı yağmur hendekleri için Manning pürüzlülük katsayısı ( $n$; QUDM, 2007).

\begin{tabular}{c|cccc|cccc}
\hline $\mathbf{d}_{\mathbf{5 0}} / \mathbf{d}_{\mathbf{9 0}}$ & \multicolumn{4}{|c|}{$\mathbf{d}_{\mathbf{5 0}} / \mathbf{d}_{\mathbf{9 0}}=\mathbf{0 . 5}$} & \multicolumn{4}{c}{$\mathbf{d}_{\mathbf{5 0}} / \mathbf{d}_{\mathbf{9} \mathbf{0}}=\mathbf{0 . 8}$} \\
\hline $\mathbf{d}_{\mathbf{5 0}}(\mathbf{m m})$ & $\mathbf{2 0 0}$ & $\mathbf{3 0 0}$ & $\mathbf{4 0 0}$ & $\mathbf{5 0 0}$ & $\mathbf{2 0 0}$ & $\mathbf{3 0 0}$ & $\mathbf{4 0 0}$ & $\mathbf{5 0 0}$ \\
\hline $\mathbf{R}_{\mathbf{h}}(\mathbf{m})$ & \multicolumn{3}{|c|}{ Manning pürüzlülük katsayıs1 $(\mathrm{n})$} & \multicolumn{3}{c}{ Manning pürüzlülük katsayıs1 (n) } \\
\cline { 2 - 8 } $\mathbf{0 . 2}$ & 0.10 & 0.14 & 0.17 & 0.21 & 0.06 & 0.08 & 0.09 & 0.11 \\
$\mathbf{0 . 3}$ & 0.08 & 0.11 & 0.14 & 0.16 & 0.05 & 0.06 & 0.08 & 0.09 \\
$\mathbf{0 . 4}$ & 0.07 & 0.09 & 0.12 & 0.14 & 0.04 & 0.05 & 0.07 & 0.08 \\
$\mathbf{0 . 5}$ & 0.06 & 0.08 & 0.10 & 0.12 & 0.04 & 0.05 & 0.06 & 0.07 \\
$\mathbf{0 . 6}$ & 0.06 & 0.08 & 0.09 & 0.11 & 0.04 & 0.05 & 0.05 & 0.06 \\
$\mathbf{0 . 8}$ & 0.05 & 0.07 & 0.08 & 0.09 & 0.04 & 0.04 & 0.05 & 0.06 \\
$\mathbf{1 . 0}$ & 0.04 & 0.06 & 0.07 & 0.08 & 0.03 & 0.04 & 0.05 & 0.05 \\
\hline
\end{tabular}

$\mathrm{R}_{\mathrm{h}}$ : Kayalar için hidrolik yarıçap $(\mathrm{m}), \mathrm{d}_{50}$ : Kayaların \%50'sinden daha küçük ortalama kaya boyutu $(\mathrm{m})$, $\mathrm{d}_{90}$ : Kayaların \%90'nından daha küçük ortalama kaya boyutu (m).

\subsubsection{Minimum Hidrolik Kalış Süresinin Hesaplanması}

Yağmur hendeklerinin iyi bir arıtma performansı gösterebilmesi için hendek içinde yağmur suyunun minimum 9 dk kalması gerekir (ARC, 1992). Bu süreden az hidrolik kalış süresine sahip hendeklerde, yağmur suyu bitki örtüsüyle yeterli süre temas edemediği için hendeğin arıtma performansı azalır. Yağmur hendeklerinde hidrolik kalış süresi Denklem 6 kullanılarak hesaplanabilir. Bu denklem aynı zamanda yağmur hendeğinin olması gereken minimum uzunluğunu hesaplarken de kullanılabilir.

$$
t_{\text {kalış }}=L_{h} /(60 * V)
$$

Burada; $t_{\text {kalış }}$ : kalış süresini (dk), $L_{h}$ : hendek uzunluğunu (m) ve $V:$ akım hızını $\left(\mathrm{m}^{2} / \mathrm{s}\right)$ ifade eder.

\subsubsection{Serbest Akım Koşulları için Savak Denklemi}

Yağmur hendeğinde meydana gelebilecek fazla suyun hendeğe zarar vermeden uzaklaştırılabilmesi için yağmur hendeklerinin genellikle uç kısımlarına savaklar inşa edilmektedir. Savakta oluşacak debi Denklem 7 kullanılarak hesaplanabilir. Bu denklemdeki savak katsayısı $\left(C_{W}\right)$ Tablo EK 2'de verilmektedir.

$$
Q_{\text {Savak }}=B * C_{W} * L_{s} * h_{s}^{3 / 2}
$$


Burada; $Q_{\text {Savak }}$ : Savaktan geçen debiyi $\left(\mathrm{m}^{3} / \mathrm{s}\right), B$ : T1kanma faktörünü (0.5 olarak kabul edilir), $C_{W}$ : Savak katsayısını, $L_{s}$ : Savak uzunluğunu (m) ve $h_{s}$ : Savağın kreti üzerindeki su derinliğini (m) ifade etmektedir.

\subsubsection{Batmış Durumdaki Çıkış Akımları için Orifis Denklemi}

Yağmur hendeğindeki savaklar suya gömülmüş halde ise orifis denkleminin kullanılmas1 gerekir. Orifis debisi $\left(Q_{\text {orifis }}\right.$ ) Denklem 8 ile hesaplanmaktadır. Bu denklemde görülen $C_{d}$ katsayısı orifis tipine göre Şekil 2'den belirlenmektedir.

$$
Q_{\text {orifis }}=B * C_{d} * A_{o} * \sqrt{\left(2 * g * h_{o}\right)}
$$

Burada; $Q_{\text {Orifis }}$ : Batmış akım durumda orifisten geçen debiyi $\left(\mathrm{m}^{3} / \mathrm{s}\right), B$ : T1kanma faktörünü (0.5 olarak kabul edilmektedir), $C_{d}$ : Debi katsayısını, $A_{o}$ : Orifisin toplam alanını $\left(\mathrm{m}^{2}\right)$, g: Yerçekimi ivmesini $\left(\mathrm{m} / \mathrm{s}^{2}\right)$ ve $h_{o}$ : Orifisin merkezi üzerindeki su derinliğini $(\mathrm{m})$ ifade etmektedir.

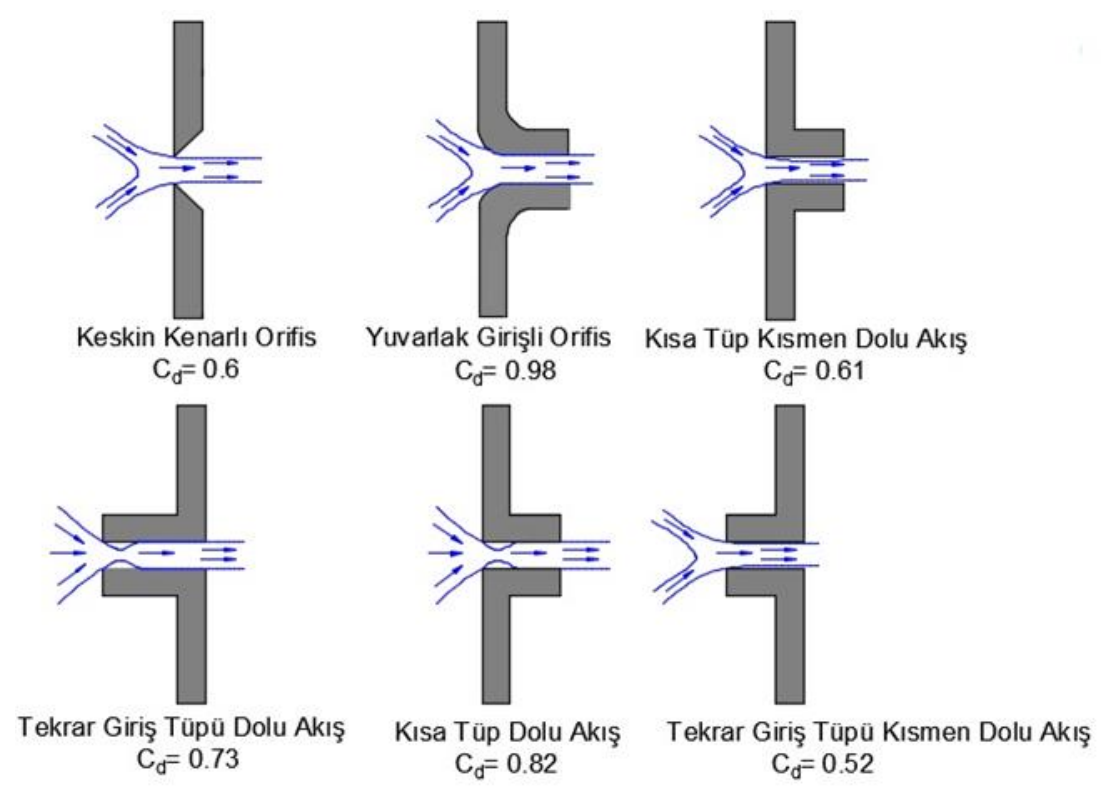

Şekil 2. Orifis tipleri ve $\mathrm{C}_{\mathrm{d}}$ katsayıları (URL-4).

2.2. Yağmur Suyu Toplama, Depolama ve Deşarj Sistemleri Yönetmeliğine Göre Kapasite Hesapları

\subsubsection{Yağmur Suyu Debisinin Hesabı}


Yağmur suyu debisini hesaplamak için yönetmelik Rasyonel metodun kullanılmasını önermektedir. Bu metot yağışla yüzeysel akış arasında lineer bir ilişki olduğunu kabul ettiği için havza alanı en fazla $5 \mathrm{~km}^{2}$ 'ye kadar olan bölgelerde kullanılabilir. Yönetmeliğe göre yağmur suyu pik debisi Denklem 9'da verilen Rasyonel metot kullanılarak hesaplanması gerekmektedir. Denklem 9'da görülen yüzeysel akış katsayısı Tablo 8'dan belirlenir. Yağışs şiddetine bağlı olarak değișen yağmur verimi $(r)$ ise Denklem 10 ile hesaplanmaktadır. Yağış şiddeti ise, yönetmelikte giriş ve akış sürelerinin toplamı ile hesaplanan geçiş süresine göre yağış şiddeti-süre-tekerrür eğrilerinden belirlenmektedir.

$$
Q=C * r * A
$$

Burada; $Q$ : pik debiyi (L/s), $C$ : yüzeysel akış katsayısını, $r$ : yağmur verimini (L/s-ha) ve $A$ : havza alanını (ha) ifade etmektedir.

$$
r=166.7 * i
$$

Burada; $r$ : yağmur verimini (L/s-ha) ve $i$ : yağış şiddetini (mm/dk) göstermektedir.

Tablo 8. Yüzeysel akış katsayısı ( $C$; 30105 Sayılı Yönetmelik).

\begin{tabular}{lc}
\hline Arazi Tipi & Yüzeysel Katsayısı \\
\hline Ticari Alanlar & \\
$\quad$ Şehir Merkezleri & $0.70-0.95$ \\
Tali Merkezler & $0.50-0.70$ \\
İkamet Alanları & \\
$\quad$ Tek Katlı Konut Alanları & $0.30-0.50$ \\
Çok Katlı Ayrık Nizam Konut Alanları & $0.40-0.60$ \\
Çok Katlı Bitişik Nizam Konut Alanları & $0.60-0.75$ \\
Mücavir Alanlar & $0.25-0.40$ \\
Çok Katlı Apartman Alanları & $0.50-070$ \\
Endüstriyel Alanlar & \\
$\quad$ Hafif Sanayi Alanları & $0.50-0.80$ \\
Ağır Sanayi Alanları & $0.60-0.90$ \\
Parklar & $0.20-0.35$ \\
Oyun Alanları & $0.20-0.40$ \\
Gelişmemiş Alanlar & $0.10-0.30$ \\
\hline
\end{tabular}

Yönetmelikte giriş süresi, yağmur suyunun giriş yapısına ulaşıncaya kadar arazide geçirdiği süre olarak tanımlanır. Giriş süresi yüzeysel toplanma süresi olarak da ifade edilir ve zemin üzerinde laminer bir yüzeysel akış meydana getirir. Giriş süresi literatürde bulunan tabaka akımının geçiş süresi ile aynı anlamdadır. Giriş süresinin hesabı için EK 5'te verilen diyagram kullanılabilir. 
Akış Süresi; yağmur suyunun kanalın en uzak noktasından toplanma noktasına gelene kadar kanal içinde geçirdiği süre olarak tanımlanır. Bu süre literatürdeki kanal akımının geçiş süresi ile aynı anlamdadır. Akış süresi Denklem 11 kullanılarak hesaplanabilir. Denklem 11'de görülen kanaldaki akım hızı; yağmur suyunda bulunan askıda katı maddelerin çökmesini engellemek için yönetmeliğin 1.3.3.1 bölümünde minimum $0.5 \mathrm{~m} / \mathrm{s}$, maksimum $5.0 \mathrm{~m} / \mathrm{s}$ olarak belirlenmiştir.

$$
t_{a k l s ̧}=L_{k} /(60 * V)
$$

Burada; $t_{\text {akış }}$ : kanal akımının akış süresini $(\mathrm{dk}), L_{k}$ : kanal akımı uzunluğunu $(\mathrm{m})$ ve $V$ : kanaldaki akım hızını $(\mathrm{m} / \mathrm{s})$ ifade etmektedir.

\subsection{Tasarım Parametreleri}

Yağmur hendeklerinin boyutlandırılmasında kullanılan parametreler; yağmur hendeğinin en kesit tipi, boyuna eğimi, şev eğimi, alt ve üst genişlikleri, uzunluğu, derinliği ve hendek içindeki akımın maksimum hızıdır. Bu parametreler aşağıda detaylı olarak açıklanmaktadır.

Yağmur hendeğinin en kesit tipi: Hendekten geçen su miktarını ve hendeğin arıtma randımanını etkilemektedir. Yağmur hendekleri kullanım amaçlarına göre; üçgen, parabolik veya trapez en kesitlerde inşa edilebilmektedirler. Üçgen en kesitli yağmur hendekleri 2 yıllık taşkın su seviyesini taşımak ve arıtmak için inşa edilirlerken, trapez ve parabolik en kesitli yağmur hendekleri 10 yıllık taşkın su seviyesini taşımak ve arıtmak için inşa edilirler (BMP Minnesota, 2001a; BMP Minnesota, 2001b). En kesit seçiminde önemli olan bir diğer faktör ise arıtılan su miktarını arttırmaktır. Bu sebeple trapez ve parabolik en kesitli yağmur hendekleri daha çok suyla temas eden yüzeye sahip olduklarından daha fazla tercih edilmektedirler.

Yağmur hendeğinin boyuna eğimi: Hendeğin boyuna eğimi hendekten geçen suyun hızı üzerinde ve dolayısıyla debi miktarında etkilidir. Ayrıca bu değer hendek tabanının oyulmasını ve arıtma randımanını da etkilemektedir. Çok fazla boyuna eğime sahip yağmur hendeklerinde yağmur suyu hendek içinde yeterli süre kalamadığından ve hendeğin tabanının oyulmasına sebep olduğundan uygulanması pratik değildir. Bu yüzden yağmur hendeklerinden daha fazla randıman alabilmek için bu hendeklerin boyuna eğiminin çok dik olmaması gerekmektedir. \%1-\%4 arasındaki boyuna eğime sahip yağmur hendeklerinde randımanın daha iyi olduğu yapılan çalışmalar sonucunda görülmüştür. \%4'ün üzerindeki eğimlerde kontrol barajlarının yapılması gerekmektedir (WSUD, 2006). Hendeğin boyuna eğimine bağlı olarak yapılması gereken kontrol barajları arasındaki mesafe Tablo 9'da verilmiştir.

Yağmur hendeğinin şev eğimi: Özellikle yol kenarlarına yapılan yağmur hendeklerine, yol yüzeyinden ulaşan yağmur suyunun arıtılmasında şev eğimleri etkilidir. Bu eğimli yüzey üzerinde 
bulunan bitki örtüsü aracılığıyla yağmur suyundaki kirletici maddelerin arıtılması sağlanır. Şev eğiminin trafiğe maruz kalan alanlarda maksimum 1:9 (dikey:yatay), trafik etkisinin olmadığ1 bahçeler, parklar ve diğer yerlerde 1:3 ile 1:10 arasında olması tavsiye edilmektedir (WSUD, 2006).

Tablo 9. Boyuna eğime bağlı kontrol barajları arasındaki mesafe (MPCA, 2000).

\begin{tabular}{cc} 
Yağmur hendeğinin boyuna eğimi (\%) & Kontrol barajlar1 arasındaki mesafe \\
\hline 1 & $60 \mathrm{~m}(200 \mathrm{ft})$ \\
2 & $30 \mathrm{~m}(100 \mathrm{ft})$ \\
4 & $15 \mathrm{~m}(50 \mathrm{ft})$ \\
6 & $10 \mathrm{~m}(33 \mathrm{ft})$ \\
8 & $8 \mathrm{~m}(25 \mathrm{ft})$ \\
10 & $6 \mathrm{~m}(20 \mathrm{ft})$ \\
\hline
\end{tabular}

Yağmur hendeklerinin alt ve üst genişlikleri: Yağmur hendeklerinin alt genişliği; hendeğin arıtma randımanı, taşıma kapasitesi ve bakımı dikkate alınarak boyutlandırılmalıdır. Alt genişlik; minimum $0.6 \mathrm{~m}$ (2 ft), maksimum $2.43 \mathrm{~m}$ (8 ft) olarak belirlenmelidir (Claytor ve Schueler, 1996). Hendek içinde kontrol barajı gibi ilave yapılar kullanılarak hendek bölümlere ayrılırsa maksimum uzunluk $4.87 \mathrm{~m}$ (16 ft)'ye kadar arttırılabilmektedir (Claytor ve Schueler, 1996). Hendeğin üst genişliği ise şev eğimine göre hesaplanmaktadır.

Yağmur hendeğinin uzunluğu: Yağmur hendeğindeki yağmur suyunun yeterince arıtılabilmesi için hendek içinde minimum $9 \mathrm{dk}$ kalması gerekmektedir (ARC, 1992). Bu süre dikkate alınarak yağmur hendeğinin uzunluğu hesaplanır. Hendek uzunluğu minimum $30 \mathrm{~m}$ olmalı ve bu uzunluktan az hesaplanan yağmur hendekleri minimum $30 \mathrm{~m}(100 \mathrm{ft})$ dikkate alınarak boyutlandırılmalıdır (ARC, 1992; BMP California, 2003). Toplam hendek uzunluğu ( $L_{H}, \mathrm{~m}$ ) Denklem 6' da görüldüğü gibi kalış süresi, minimum $9 \mathrm{dk}$ alınarak ve suyun hızı $(V, \mathrm{~m} / \mathrm{s})$ belli sınırlarda seçilerek hesaplanmaktadır (ARC, 1992).

Yağmur hendeğinin derinliği: Üçgen en kesitli yağmur hendeklerinin toplam derinlikleri 2 yıllık taşkın su seviyesi ve hava payının toplamından oluşurken, trapez ve parabolik en kesitli yağmur hendeklerinin toplam derinlikleri 10 yıllık taşkın su seviyesi ve hava payının toplamından oluşmaktadır. Yağmur hendeklerinde hava payı bırakılmasının nedeni; rüzgar ve deprem gibi etkilerden dolayı hendek içindeki suyun taşarak güvenlik problemlerine sebep olmasını engellemektir. Yağmur hendeklerinde yaklaşık 15 cm'lik (6 inç) hava payı bırakılmalıdır (Claytor ve Schueler, 1996; BMP Minnesota, 2001a; BMP Minnesota, 2001b).

Maksimum hız; yağmur hendeği tabanının ve hendekte biriktirilen sedimentin oyulmasını önlemek için hendek içindeki akım hızının belli bir seviyede tutulması gerekmektedir. Akım hızının azaltılması için; belli aralıklarla kontrol barajları inşa edilebileceği gibi, giriş akımlarının önüne riprap yapısı ve şev kenarlarına ince çakı1 diyafram (yol kaplamasından gelen akımlar için) yerleştirilebilir. 
Yağmur hendeğinin 2 ve 10 yıllık taşkın debisine göre tasarlanması halinde; hendek içindeki akım hızının $0.5 \mathrm{~m} / \mathrm{s}$ 'den, 50 ve 100 yıllık taşkın debisine göre tasarlanması halinde ise; akım hızının 2.0 m/s'den küçük olması gerekmektedir (WSUD, 2006). Ayrıca yağmur hendekleri derinlik x hız kontrollerini de sağlamalıdır. Düşük riskli bölgelerde derinlik x hız $0.6 \mathrm{~m}^{2} / \mathrm{s}$ 'den, yüksek riskli bölgelerde ise $0.4 \mathrm{~m}^{2} / \mathrm{s}$ 'den daha az olmalıdır (WSUD, 2006). Tablo 2.3'te tüm tasarım parametrelerinin değerleri özetlenmektedir.

\subsection{Yağmur Hendeklerinin Maliyet Hesabı}

\subsubsection{Inşaat Maliyeti}

Yağmur hendeklerinin inşaat maliyetleri diğer yağmursuyu yönetim uygulamalarına kıyasla daha düşük olmasına rağmen tasarım maliyetleri daha yüksektir. Bunun en önemli sebebi tasarımı kolay olmasına rağmen yeterli yetişmiş elemanın bulunmamasıdır. Bu makalenin bu konuda yetişecek kişilere 1şık tutacağı düşünülmektedir.

Tablo 10. Yağmur hendeğinin inşaat maliyeti (SEWRPC, 1991).

\begin{tabular}{|c|c|c|c|c|c|c|c|c|}
\hline \multirow[b]{2}{*}{ Unsur } & \multirow[b]{2}{*}{ Birim } & \multirow[b]{2}{*}{ Boyut } & \multicolumn{3}{|c|}{ Birim Maliyet (TL) } & \multicolumn{3}{|c|}{ Toplam Maliyet (TL) } \\
\hline & & & Düșük & Orta & Yüksek & Düșük & Orta & Yüksek \\
\hline Organizasyon / Planlama & $\begin{array}{l}{ }^{\text {a}} \text { Yağmur } \\
\text { Hendeği }\end{array}$ & 1 & 381,99 & 978,18 & $1.574,37$ & 381,99 & 978,18 & $1.574,37$ \\
\hline \multicolumn{9}{|l|}{ Bölgeyi Hazırlama } \\
\hline${ }^{\mathrm{b}}$ Temizleme & Dönüm & 0.5 & $7.854,00$ & $13.566,00$ & $19.278,00$ & $3.927,00$ & $6.783,00$ & $9.639,00$ \\
\hline c Kök Sökme & Dönüm & 0.25 & $13.566,00$ & $18.564,00$ & $23.562,00$ & $3.391,50$ & $4.641,00$ & $5.890,50$ \\
\hline \multicolumn{9}{|l|}{ Genel } \\
\hline${ }^{\mathrm{d}}$ Kazma (Hafriyat) & $\mathrm{m}^{3}$ & 284 & 9,81 & 17,29 & 24,77 & $2.786,04$ & $4.910,08$ & $7.033,26$ \\
\hline $\begin{array}{l}\text { Toprağ1 Düzleştirme / } \\
\text { Sürme } \\
\text { Bölgeyi İyileştirme }\end{array}$ & $\mathrm{m}^{2}$ & 1011 & 0,85 & 1,49 & 2,14 & 863,46 & $1.511,04$ & $2.158,49$ \\
\hline${ }^{\mathrm{f}}$ Tohum Ekme ve Malç & $\mathrm{m}^{2}$ & 1011 & 1,71 & 4,27 & 6,83 & $1.726,79$ & $4.317,27$ & $6.907,66$ \\
\hline $\begin{array}{l}\text { "QÇimle Kaplama } \\
\text { Ara Toplam }\end{array}$ & $\mathrm{m}^{2}$ & 1011 & 5,12 & 10,25 & 15,37 & $\begin{array}{c}5.180,77 \\
18.258\end{array}$ & $\begin{array}{l}10.361,54 \\
33.502,11\end{array}$ & $\begin{array}{l}15.542,10 \\
48.745,38\end{array}$ \\
\hline Hata Pay1 & $\begin{array}{l}\text { Yağmur } \\
\text { Hendeği }\end{array}$ & 1 & $\% 25$ & $\% 25$ & $\% 25$ & 4.564 & 8.376 & 12.186 \\
\hline Yaklaşık Toplam & & & & & & 22.900 & 41.900 & 61.000 \\
\hline
\end{tabular}

a Yağmur Hendeği: $0.7 \mathrm{~m}$ taban genişliği, $3.0 \mathrm{~m}$ üst genişlik, 3:1 şev eğimi ve $700 \mathrm{~m}$ uzunluk,

b Temizlenen Alan: (Üst genişlik + 3.0) x yağmur hendeği uzunluğu,

${ }^{c}$ Kök Sökülen Alan: Üst genişlik x yağmur hendeği uzunluğu,

d Kazılan Hacim: (0.67 x Üst genişlik x yağmur hendeği derinliği) x yağmur hendeği uzunluğu (Parabolik Kesit),

e Sürülen Alan: [Üst genişlik $+8 *(\text { hendek derinliği) })^{2} / 3 *($ üst genişlik)] x yağmur hendeği uzunluğu (Parabolik Kesit),

f Tohum Ekilen Alan: Temizlenen alan x 0.5,

g Çimle Kaplanan Alan: Temizlenen alan x 0.5. 
Yağmur hendeklerinin inşaat maliyetleri temizleme, kök sökme, kazma, toprağı düzleştirme, tohum ekme, malçlama ve hendeği çimle kaplama maliyetlerinin toplamından oluşmaktadır. Bu toplam maliyet ortalama olarak yağmur hendeğinin metre karesi başına 19.20 TL (ft2 başına 0.50 \$) olarak kabul edilebilir ve detaylı maliyetler Tablo 10'da verilmektedir (SEWRPC, 1991). Daha güncel bir çalışmaya göre yağmur hendeğinin metre karesi başına 35.7 TL (m2 başına 10 \$) inşaat maliyeti bulunmaktadır (WSUD, 2004). \%2'den az boyuna eğime sahip yağmur hendeklerinde bu maliyete metre başına 107.1 TL (30 \$) eklenmektedir. Bu ek maliyeti yağmur hendeğinin tabanında oluşturulan filtre, geçiş ve altdrenaj sistemleri meydana getirmektedir (WSUD, 2004). Bu makalede verilen bütün maliyet hesap tablolarında dolar kuru için 15.05.2017'de Merkez Bankası tarafından verilen kur (3.57 TL) esas alınmıştır.

\subsubsection{Bakım Maliyeti}

Yağmur hendeklerinin bakımı genellikle çim biçme ve bakımı, hendek içinde biriken çöplerin uzaklaştırılması, tohum ekme ve gübreleme, eğim kontrolü, sulama ve bitkilendirme işlemlerinden oluşmaktadır. Örnek bir yağmur hendeğinin bakım maliyeti Tablo 11'de verilmektedir (WSUD, 2004).

Tablo 11. Yağmur hendeğinin bakım maliyeti (WSUD, 2004).

\begin{tabular}{lccc} 
& & \multicolumn{2}{c}{ Yağmur hendeği boyutu } \\
\cline { 3 - 4 } Unsur & Tahmini Maliyet (TL) & A (TL) & B (TL) \\
\hline Biçme & $5.78 / 100 \mathrm{~m}^{2}$ & 944.6 & 1571.15 \\
Genel çim bakımı & $57.84 / 100 \mathrm{~m}^{2}$ & 1060.3 & 1783.21 \\
Çöp/döküntü uzaklaştırma & $3.4 / \mathrm{m}^{2}$ & 607.25 & 607.25 \\
Tohum ekme /gübreleme & $2.32 / \mathrm{m}^{2}$ & 38.55 & 67.47 \\
Kontrol ve genel yönetim & $4.82 / \mathrm{m}^{2}$ & 1502.9 & 1502.97 \\
Toplam & $\mathbf{1 1 . 1 7} / \mathbf{~ m}^{\mathbf{2}}$ & $\mathbf{4 1 5 3 . 6}$ & $\mathbf{5 5 3 2 . 0 5}$ \\
\hline
\end{tabular}

A: $0.5 \mathrm{~m}$ derinlik, $0.3 \mathrm{~m}$ alt genişlik, $3 \mathrm{~m}$ üst genişlik; B: $1 \mathrm{~m}$ derinlik, $1 \mathrm{~m}$ alt genişlik, $7 \mathrm{~m}$ üst genişlik.

\section{Araştırma Bulguları}

Bu bölümde örnek bir yağmur hendeğinin kapasite hesabı hem uluslararası literatüre göre hem de 30105 sayılı yağmur suyu toplama, depolama ve deşarj sistemleri yönetmeliğine göre yapılmıştır. Bu hesap için İstanbul ili Kadıköy ilçesi Göztepe bölgesi çalışma alanı olarak belirlenmiştir. Çalışma alanı Şekil 3 'te görüldüğü gibidir. 


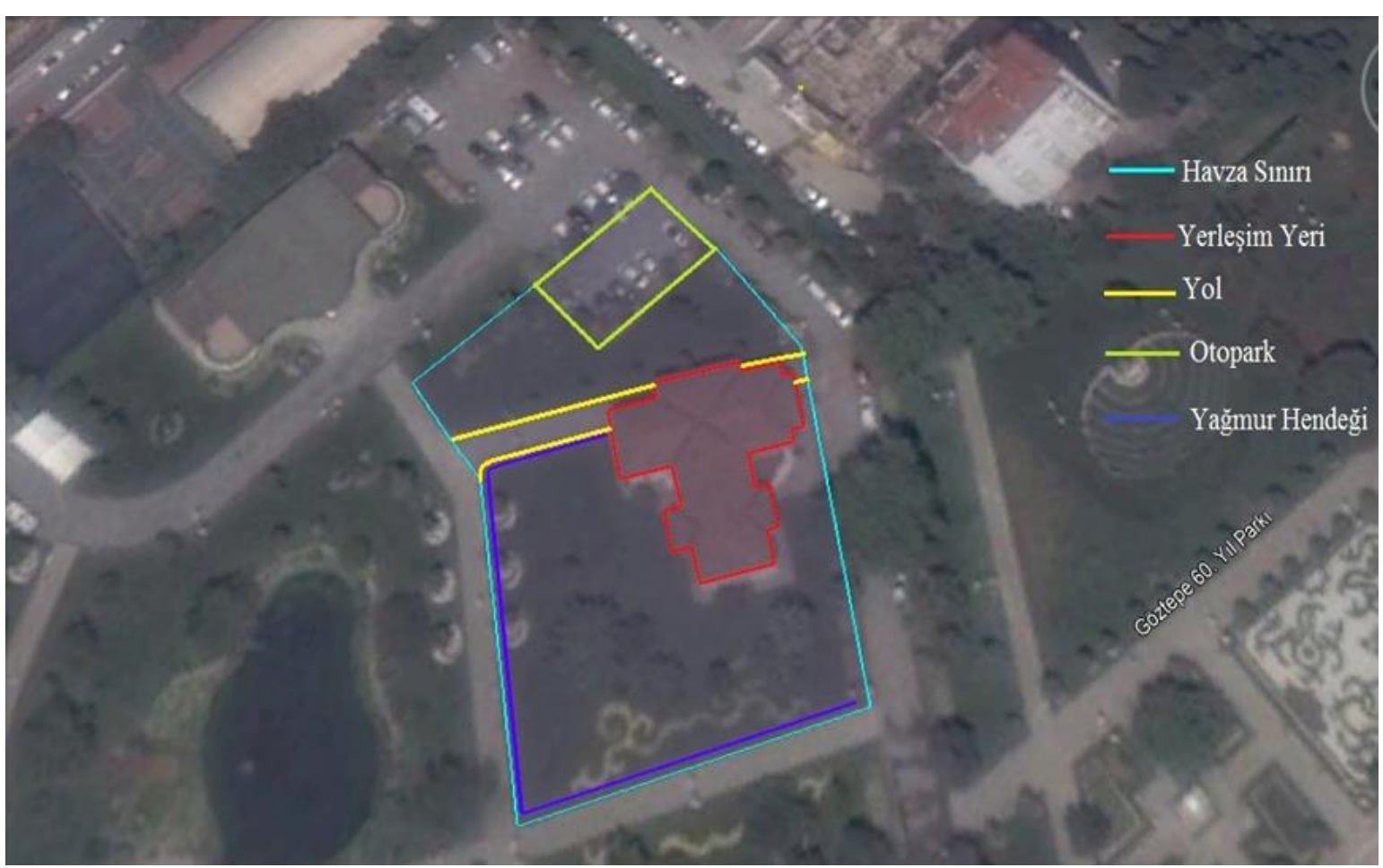

Şekil 3. Yağmur hendeği çalışma alanı

\section{1. Örnek Bir Yağmur Hendeği Hesabı}

Üst yüzeyi bitki örtüsü ile kaplanmış yağmur hendeğine ait örnek bir uygulama aşağıda detaylı şekilde açıklanmıştır. Bu örneğe ait veriler şunlardır;

$\underline{\text { Yağmur hendeğine ve havzaya ait bilgiler; }}$

- Toplam havza alanı: $2500 \mathrm{~m}^{2}$ 'dir ve bu alanın dağılımı; yeşil alan: $1289 \mathrm{~m}^{2}$, yerleşim bölgesi: $379 \mathrm{~m}^{2}$, otopark: $260 \mathrm{~m}^{2}$, yol: $190 \mathrm{~m}^{2}$, ve yağmur hendeği: $382 \mathrm{~m}^{2}$ şeklindedir,

- Arazi kullanımı: Yol ve otoparkların dahil olduğu düşük yoğunluklu kentsel yerleşim,

- Arazinin ve hendeğin boyuna eğimi: \%2,

- Toplam akım yolu uzunluğu $\left(L_{T}\right): 90 \mathrm{~m}$,

- Yağmur hendeğinin toplam uzunluğu $\left(L_{h}\right): 90 \mathrm{~m}$,

- Horton pürüzlülük katsayısı $(n *)$ : 0.20 (Tablo 1'de çimler bölümünde verilen aralıktan seçilmiştir),

- Savak katsayısı (Cw): 1.66 (0.2 m genişlik, 0.2 m savak yüküne göre EK 2'den seçilmiştir),

- Debi katsayısı $\left(\mathrm{C}_{\mathrm{d}}\right)$ : 0.6 (keskin kenarlı orifís tipi için Şekil 2'den seçilmiştir),

- $\mathrm{Bu}$ yağmur hendeğinin hesabı için İstanbul ili Göztepe meteoroloji istasyonuna ait yağıŞ şiddeti-süre tekerrür eğrileri kullanılmıştır ve bu eğriler EK 3'te verilmiştir (MGM). 


\subsubsection{Literatür Araştırmasına Göre Kapasite Hesapları}

\subsubsection{Pik Debinin Hesaplanması}

Yağmur hendeklerine ait pik debi hesapları 10 ve 100 yıllık taşkın debileri dikkate alınarak yapılmaktadır. $\mathrm{Bu}$ iki hesap birbirine çok benzemesine rağmen aşağıda detaylı olarak açıklanmaktadır.

\section{a) 10 yıllık taşkın debisine göre;}

Denklem 2 ve EK 3'te verilen İstanbul İli Göztepe meteoroloji istasyonuna ait yağış şiddetisüre-tekerrür eğrileri kullanılarak 10 yıllık taşkın debisine göre geçiş süresinin hesabında; toplam hendek boyu uzunluğunun en fazla 50 metresi tabaka akışı olarak kabul edilip geri kalan 40 metresinin kanal akışı şeklinde hesaplanması gerekir.

$$
t_{\text {tabaka }}=6.94 * \frac{(50 * 0.20)^{0.6}}{(73)^{0.4} *(0.02)^{0.3}}=16.05 d k
$$

Yukarıdaki denklemde $t_{\text {tabaka }}$ ile EK 3 'te verilen İstanbul İli Göztepe meteoroloji istasyonuna ait yağış şiddeti-süre-tekerrür eğrilerindeki 10 yıllık taşkına ait yağış şiddeti $\left(\mathrm{I}_{10}\right)$ değeri eşleşinceye kadar iterasyon yapılmalıdır.

$$
t_{\text {kanal }}=(40) /(60 * 0.7)=0.95 d k
$$

Ortalama akım hızı, EK 4'te verilen ortalama akarsu hızına göre $0.7 \mathrm{~m} / \mathrm{s}$ kabul edilerek kanal akımı geçiş süresi $\left(t_{\text {kanal }}\right)$ hesaplanmıştır.

$$
t_{c}=t_{\text {tabaka }}+t_{\text {kanal }}=17.0 d k
$$

Toplam geçiş süresine ( $\left.\mathrm{t}_{c}\right)$ göre 10 yıllık yağış şiddeti ( $\left.\mathrm{I}_{10}\right)$, EK 3 'te verilen İstanbul İli Göztepe meteoroloji istasyonuna ait yağış şiddeti-süre-tekerrür eğrilerinden 71 mm/sa olarak bulunur.

\section{b) 100 yıllık taşkın debisine göre;}

$$
t_{\text {tabaka }}=6.94 * \frac{(50 * 0.20)^{0.6}}{(140)^{0.4} *(0.02)^{0.3}}=12.3 d k
$$


Yukarıdaki denklemde $t_{\text {tabaka }}$ ile EK 3'te verilen İstanbul İli Göztepe Meteoroloji İstasyonuna ait yağış şiddeti-süre-tekerrür eğrilerindeki 100 yıllık taşkına ait yağış şiddeti ( $\left.\mathrm{I}_{100}\right)$ değeri eşleşinceye kadar iterasyon yapılmalıdır.

$$
t_{\text {kanal }}=(40) /(60 * 0.7)=0.95 d k
$$

Ortalama akım hızı, EK 4’te verilen ortalama akarsu hızına göre 0.7 m/s kabul edilerek kanal akımı geçiş süresi $\left(t_{\text {kanal }}\right)$ hesaplanmıştır.

$$
t_{c}=t_{\text {tabaka }}+t_{\text {kanal }}=13.2 d k
$$

Toplam geçiş süresine $\left(\mathrm{t}_{\mathrm{c}}\right)$ göre 100 y1llık yağış şiddeti ( $\mathrm{I}_{100)}$, EK 3 ’te verilen İstanbul İli Göztepe Meteoroloji İstasyonuna ait yağış şiddeti-süre-tekerrür eğrilerinden $\mathbf{1 3 8}$ mm/sa olarak bulunur.

10 yıllık tekrarlanma sıklığına ve 1 saatlik yağış süresine bağlı olarak yağış şiddeti $\left({ }^{1} \mathrm{I}_{10}\right)$ değeri yine İstanbul İli Göztepe meteoroloji istasyonuna ait yağış şiddeti-süre-tekerrür eğrilerinden belirlenir. Bu değer EK 3'ten 31 mm/sa olarak okunmuştur. Aynı zamanda Tablo 2'den bölgenin geçirimsizlik oranı $\left(f_{i}\right)$ düşük yoğunluklu kentsel bölgeler (yollar dahil) için $\mathbf{0 . 7}$ olarak seçilebilir. Bu değerlere göre; Tablo 3'ten 10 yıllık yüzeysel akış katsayısı $\left(\mathrm{C}_{10}\right) 0.6$ ile 0.8 arasındaki 0.7 değerine göre hesaplanarak $\mathbf{0 . 7 2 5}$ olarak bulunur. 100 yıllık yüzeysel akış katsayısı ( $\left.\mathrm{C}_{100}\right)$ ise Tablo 5 'te verilen frekans faktörüne göre Denklem 4 ile hesaplanır.

$$
C_{100}=1.2 * 0.725=0.870
$$

Bulunan C100 değeri 1'den küçük olduğundan aynen kullanılır (1'den büyük olması durumunda 1 alınması gerekir). Tüm bu değerler bulunduktan sonra Denklem 1 kullanılarak 10 ve 100 yıllık pik debiler hesaplanır.

$$
\begin{aligned}
& Q_{10}=\frac{0.725 * 71 * 0.25}{360}=0.036 \mathrm{~m}^{3} / \mathrm{s} \\
& Q_{100}=\frac{0.870 * 138 * 0.25}{360}=0.083 \mathrm{~m}^{3} / \mathrm{s}
\end{aligned}
$$

\subsubsection{Yağmur Hendeğinin Kapasitesinin Hesaplanması}


İnşa edilmesi planlanan yağmur hendeğinin en kesit tipi ve boyutları Şekil 4 'te verilmiştir. Bu en kesite ait parametrelerin hesabı, EK 1'deki trapez en kesit formülleri kullanılarak Aw $=0.52 \mathrm{~m}^{2}$, $\mathrm{P}_{\mathrm{W}}=4.22 \mathrm{~m}$ ve $\mathrm{R}_{\mathrm{h}}=0.123 \mathrm{~m}$ olarak bulunmuştur. Hidrolik yarıçap $\left(\mathrm{R}_{\mathrm{h}}\right)$ ve hendek eğimi $(\mathrm{S})$ kullanılarak Tablo 6'dan Manning katsayısı (n) yaklaşık olarak 0.072 olarak okunmuştur.

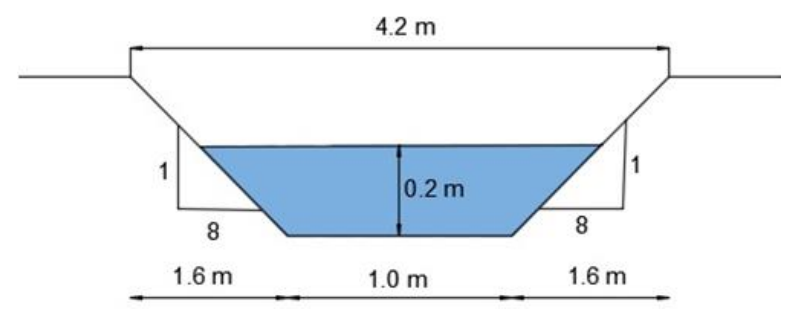

Şekil 4. Trapez en kesit.

Daha sonra Denklem 5 kullanılarak hendekteki ortalama hız hesaplanır. Bu değer süreklilik denklemine göre hendek en kesit alanı ile çarpılarak hendek kapasitesi belirlenir. Hendek kapasitesi mutlaka hendek ömrü için beklenen pik debiyi taşımaya yeterli olmalıdır.

$$
\begin{aligned}
& V_{\text {ort. }}=\frac{1}{0.072} *(0.123)^{2 / 3} *(0.02)^{1 / 2}=0.485 \mathrm{~m} / \mathrm{s} \\
& Q_{\text {kap }}=0.485 * 0.52=0.253 \mathrm{~m}^{3} / \mathrm{s}
\end{aligned}
$$

Hesaplanan 10 yıllık $\left(0.036 \mathrm{~m}^{3} / \mathrm{s}\right)$ ve $100\left(0.083 \mathrm{~m}^{3} / \mathrm{s}\right)$ yıllık pik debilerden daha büyük taşıma kapasitesi $\left(0.253 \mathrm{~m}^{3} / \mathrm{s}\right)$ bulunduğu için yağmur hendeği bu akımı mevcut boyutlarıyla güvenli bir şekilde taşıyabilecektir. Yağmur hendeğinin kapasitesinin pik debiden küçük olması durumunda ise; boyutlar arttırılarak tüm hesapların tekrarlanması gerekir.

\subsubsection{Minimum Hidrolik Kalış Süresinin Hesaplanması}

Yağmur hendeğinde bulunan yağmur suyunun kalış süresi, hendeğin sızma ve arıtma performansı açısından faydalı iken sivrisinek üremesi açısından olumsuz sonuçlar doğurabilmektedir. $\mathrm{Bu}$ yüzden suyun minimum $9 \mathrm{dk}$ ve maksimum 48 saat hendek içinde kalması gerekmektedir. 10 ve 100 yıllık taşkın debileri için minimum hidrolik kalış süresi; süreklilik denklemi ve Denklem 6 kullanılarak hesaplanır. 


\section{a) 10 yıllık taşkın debisi için;}

Bu hesaplamada hendeğe ait hız, 10 yıllık taşkın pik debisi ve hendek en kesit alanı kullanılarak bulunmuştur.

$$
\begin{aligned}
& v=\frac{Q_{10}}{A}=\frac{0.036}{0.52}=0.069 \mathrm{~m} / \mathrm{s} \\
& t_{\text {kalls }}=90 /(60 * 0.069) \\
& t_{\text {kalls }}=22 d k>9 d k \text { olduğundan uygundur. }
\end{aligned}
$$

\section{b) 100 yıllık taşkın debisi için;}

$\mathrm{Bu}$ hesaplamada hendeğe ait hız, 100 yıllık taşkın pik debisi ve hendek en kesit alanı kullanılarak bulunmuştur.

$$
\begin{aligned}
& v=\frac{Q_{100}}{A}=\frac{0.083}{0.52}=0.159 \mathrm{~m} / \mathrm{s} \\
& t_{\text {kalıs }}=90 /(60 * 0.159) \\
& t_{\text {kalıs }}=9.5 d k>9 d k \text { olduğundan uygundur. }
\end{aligned}
$$

10 ve 100 yıllık taşkın debisine göre yapılan hesapta kalış süresinin 9 dakikadan daha küçük çıkması durumu için yağmur hendeğinin uzunluğu, hendek içindeki suyun kalış süresi minimum $9 \mathrm{dk}$ alınarak tekrar hesaplanmalı ve bu hesaba göre yağmur hendeğinin minimum uzunluğu belirlenmelidir. Denklem 6 kullanılarak yağmur hendeğinin olması gereken minimum uzunluğu hesaplanabilir.

\subsubsection{Hzz Kontrolü}

Değişik derinlikler için Manning denklemi ile bulunan hız değerleri ve hendek en kesit alanının çarpımı ile bulunan debi hacimleri Tablo 12'de verilmiştir. 
10 yıllık taşkın debisine $\left(0.036 \mathrm{~m}^{3} / \mathrm{s}\right)$ göre derinlik Tablo 12 'den $0.078 \mathrm{~m}$ olarak okunur. $\mathrm{Bu}$ değer yardımıyla Tablo 12'den Manning katsayısı, hidrolik yarıçap ve eğim değerleri sırası ile 0.081, $0.055 \mathrm{~m}$ ve 0.02 olarak belirlenir. Bulunan tüm değerler Denklem 5'te yerine konularak 10 yıllık taşkın meydana geldiğinde hendekte oluşacak hız bulunur. Bulunan hız değeri 10 yıllık taşkın debisi için $0.5 \mathrm{~m} / \mathrm{s}^{\prime}$ den küçük olmalıdır. Benzer işlemler 100 yıllık taşkın $\left(0.083 \mathrm{~m}^{3} / \mathrm{s}\right)$ meydana gelmesi durumuna göre tekrarlanarak 100 yıllık taşkın debisi sırasında oluşacak hız hesaplanabilir. Bu değer hendek tabanının oyulmasını önlemek için $2.0 \mathrm{~m} / \mathrm{s}$ 'den küçük olmalıdır.

$$
\begin{aligned}
& V_{10}=\frac{1}{0.081} *(0.055)^{2 / 3} *(0.02)^{1 / 2}=0.25 \mathrm{~m} / \mathrm{s}<0.5 \mathrm{~m} / \mathrm{s} \text { olduğundan uygundur. } \\
& V_{100}=\frac{1}{0.081} *(0.083)^{2 / 3} *(0.02)^{1 / 2}=0.33 \mathrm{~m} / \mathrm{s}<2.0 \mathrm{~m} / \mathrm{s} \text { olduğundan uygundur. }
\end{aligned}
$$

\begin{tabular}{|c|c|c|c|c|c|}
\hline Derinlik (m) & $\begin{array}{c}\text { Manning } \\
\text { Katsayısı (n) }\end{array}$ & $\begin{array}{c}\text { Hidrolik } \\
\text { Yarıçap }\left(\mathbf{R}_{\mathbf{h}}\right)\end{array}$ & $\begin{array}{c}\text { Hendek } \\
\text { Eğimi (S) }\end{array}$ & $\begin{array}{l}\text { Hendek En Kesit } \\
\text { Alanı }\left(\mathbf{m}^{2}\right)\end{array}$ & Debi $\left(\mathbf{m}^{3} / \mathbf{s}\right)$ \\
\hline 0,025 & 0,081 & 0,021 & 0,02 & 0,030 & 0,004 \\
\hline 0,05 & 0,081 & 0,039 & 0,02 & 0,070 & 0,014 \\
\hline 0,10 & 0,081 & 0,069 & 0,02 & 0,180 & 0,053 \\
\hline 0,11 & 0,081 & 0,075 & 0,02 & 0,207 & 0,064 \\
\hline 0,12 & 0,081 & 0,080 & 0,02 & 0,235 & 0,076 \\
\hline 0,13 & 0,081 & 0,086 & 0,02 & 0,265 & 0,090 \\
\hline 0,14 & 0,081 & 0,091 & 0,02 & 0,297 & 0,105 \\
\hline 0,15 & 0,081 & 0,097 & 0,02 & 0,330 & 0,121 \\
\hline 0,16 & 0,080 & 0,102 & 0,02 & 0,365 & 0,141 \\
\hline 0,17 & 0,078 & 0,107 & 0,02 & 0,401 & 0,164 \\
\hline 0,18 & 0,076 & 0,113 & 0,02 & 0,439 & 0,191 \\
\hline 0,19 & 0,074 & 0,118 & 0,02 & 0,479 & 0,220 \\
\hline 0,20 & 0,072 & 0,123 & 0,02 & 0,520 & 0,253 \\
\hline
\end{tabular}

Tablo 12. Hesaplanan debi - derinlik ilişkisi.

\subsubsection{Derinlik x Hız Kontrolü}

10 yıllık taşkın debisine sahip düşük riskli bölgeler için;

$0.078 * 0.25=0.0195 \mathrm{~m}^{2} / \mathrm{s}<0.6 \mathrm{~m}^{2} / \mathrm{s}$ olduğundan uygundur.

100 yıllık taşkın debisine sahip yüksek riskli bölgeler için;

$0.125 * 0.33=0.0412 \mathrm{~m}^{2} / \mathrm{s}<0.4 \mathrm{~m}^{2} / \mathrm{s}$ olduğundan uygundur.

\subsubsection{Savak Uzunluğunun Hesaplanması ve Boyutlandırılması}


10 yıllık taşkın debisini taşıyan yağmur hendekleri için savak uzunluğu, Denklem 5 kullanılarak hesaplanmaktadir.

$$
0.036=0.5 * 1.66 * L_{s} *(0.2)^{3 / 2}
$$

Buradan savak uzunluğu 0.48 m olarak bulunur. Bulunan değer savağın toplam çevre uzunluğu olduğu için savak $0.12 \mathrm{~m}$ x $0.12 \mathrm{~m}$ olarak boyutlandırılabilir. Aynı hesap 100 yıllık taşkın debisi için de tekrarlanmalıdır. Böylece 100 yıllık taşkın olması halinde gerekli savak uzunluğu ve boyutu hesaplanır. Hendek ömrüne ve hendeğin bulunduğu yere göre bir başka deyişle hendeğin önemine göre kaç yıllık taşkına göre tasarlanan savağın imal edileceğine karar verilir. Bu adımlar orifis boyutlandırması içinde geçerlidir.

\subsubsection{Batmış Durumdaki Çıkış Akımlarının Boyutlandırııması}

10 yıllık taşkın debisi için suya gömülmüş halde bulunan çıkış akımları Denklem 8 kullanarak hesaplanmaktadır.

$$
0.036=0.5 * 0.6 * A_{o} * \sqrt{2 * 9.81 * 0.2}
$$

Buradan orifisin toplam alanı $\left(\mathrm{A}_{\mathrm{o}}\right) 0.060 \mathrm{~m}^{2}$ olarak bulunur ve orifis $0.24 \mathrm{~m} \mathrm{x} 0.24 \mathrm{~m}$ olacak şekilde boyutlandırılabilir.

\subsubsection{Yağmur Suyu Toplama, Depolama ve Deşarj Sistemleri Yönetmeliğinde Göre} Kapasite Hesabı

\subsubsection{Pik Debinin Hesaplanması}

Yüzeysel akışın meydana getirdiği pik debinin hesaplanabilmesi için giriş ve akış sürelerinin toplamından oluşan geçiş süresinin bilinmesi gerekir. Giriş süresi EK 5'teki diyagram kullanılarak hesaplanabilir. Yönetmelikte giriş ve akış akımlarının uzunlukları hakkında bir ayrım yoktur. Bu yüzden giriş süresinin hesabında yüzeysel akış uzunluğu uluslararası literatürde belirtildiği şekilde maksimum 50 metre olarak alınmış, geri kalan 40 metresi ise akış süresi olarak değerlendirilmiştir. $\mathrm{Bu}$ hesap sonucu giriş süresi $\left(t_{\text {girişs }}\right)$ yaklaşık $17.5 \mathrm{dk}$ olarak belirlenmiştir. Akış süresi ise Denklem 
11 kullanılarak hesaplanabilir. Akış süresinin hesabında gerekli olan hız, yönetmelikte geçen minimum hız $(0.5 \mathrm{~m} / \mathrm{s})$ şartı dikkate alınarak belirlenmiştir.

$$
\begin{aligned}
& t_{a k l s}=40 /(60 * 0.5)=1.33 d k . \\
& t_{c}=t_{\text {giriş }}+t_{a k l s ̧}=19 d k .
\end{aligned}
$$

Bulunan toplam geçiş süresine $\left(t_{c}=19 d k\right.$.) göre EK 3'te verilen İstanbul ili Göztepe meteoroloji istasyonuna ait yağış şiddeti-süre-tekerrür eğrileri kullanılarak 10 yıllık yağış şiddeti 67 $\mathbf{m m} / \mathbf{s a}, 100$ yıllık yağış şiddeti ise $100 \mathbf{~ m m} / \mathbf{s a}$ olarak belirlenir. Bu değerler mm/dk cinsinden ifade edilerek Denklem 10 yardımı ile 10 ve 100 yıllık tekerrür aralığına sahip yağışlar için yağmur verimi hesaplanır. Daha sonra Denklem 9 kullanılarak 10 ve 100 yıllık tekerrür aralığına sahip yağışlar için pik debi hesaplanır. Denklem 9'daki yüzeysel akış katsayısı Tablo 8'den çok katlı ayrık nizam konut alanları bölümünden 0.5 olarak seçilir.

a) 10 yıllık taşkın debisine göre yağmur verimi;

$$
r=166.7 *(67 / 60)=186.14(L / s-h a)
$$

b) 100 yıllık taşkın debisine göre yağmur verimi;

$$
r=166.7 *(100 / 60)=277.83(L / s-h a)
$$

a) $\mathbf{1 0}$ yıllık taşkın debisine göre pik debi;

$$
\begin{aligned}
& Q_{10}=0.5 * 186.14 * 0.25 \\
& Q_{10}=23.26 \mathrm{~L} / \mathrm{s}=0.02326 \mathrm{~m}^{3} / \mathrm{s}
\end{aligned}
$$

b) 100 yıllık taşkın debisine göre pik debi;

$$
\begin{aligned}
& Q_{100}=0.5 * 277.83 * 0.25 \\
& Q_{100}=34.72 \mathrm{~L} / \mathrm{s}=0.03472 \mathrm{~m}^{3} / \mathrm{s}
\end{aligned}
$$




\section{Sonuçlar ve Öneriler}

Gün geçtikçe artan şehirleşme oranı ve buna bağlı olarak artan yüzey geçirimsizliği ve yüzey kirliliği yağmur suyunun kirlilik derecesini arttırmaktadır. Yağmur hendekleri, şehirleşmenin bu olumsuz etkisini bertaraf edecek bir uygulamadır (Revitt ve diğ., 2017). Şehirleşme oranı yüksek olan bölgelerde bu hendeklerin özellikle yol kenarlarında kullanılması yaygındır. Böylece hendekler; trafik etkisinden dolayı kirlenen yağmur suyunun arıtılmasına ve taşınmasına katkı sağlar (Flanagan ve diğg., 2017). Yağmur hendekleri genellikle küçük alanlı (2 ile 4 hektar) bölgelerin iyileştirilmesinde kullanılmaktadır. Daha büyük alanlı bölgelerde ise bu hendekler birbirleri ile bir bütün halinde çalışarak (özellikle yol kenarlarındaki hendekler birbirlerine menfezler ile bağlanarak) bölgenin iyileştirilmesine yardımcı olabilirler. Ayrıca ekonomik bir uygulama olması ile diğer yağmursuyu uygulamalarına karşı iyi bir seçenektir. Bu faydalarından dolayı yağmur hendeklerinin yurtdışında olduğu gibi ülkemizde de yaygınlaştırılması gerekmektedir.

$\mathrm{Bu}$ çalışmada yağmur hendeklerinin kapasite ve maliyet hesapları hakkında literatür araştırması yapılarak İstanbul ili Göztepe bölgesi için bir yağmur hendeği tasarlanmıştır. Üstelik bu hendek hem uluslararası literatüre hem de 30105 sayılı yağmur suyu toplama, depolama ve deşarj sistemleri yönetmeliğine göre hesaplanmıştır. Bu iki hesap kıyaslandığında özellikle 100 yıllık taşkın debisi için büyük fark oluşmaktadır. Bu fark yüzeysel akış katsayısından kaynaklanmaktadır.

Yüzeysel akış katsayısının hesaplabında; uluslararası literatür 10 ve 100 yıllık taşkın debileri için ayrı ayrı hesap yapılmasını tavsiye ederken, yeni 30105 sayılı yönetmelikte böyle bir ayrıma gidilmemiştir. Bu durum pik debinin hesaplanmasında 100 yıllık taşkın debisi için büyük farklara neden olmaktadır. Bu ise iklim değişikliği gözönüne alındığında fark daha önem kazanmaktadır.

Kısaca; uluslararası literatürün hendek hesaplarını detaylı şekilde açıkladığı, fakat 30105 sayılı yönetmeliğin pik debinin hesabı dışında yağmur hendekleri ile ilgili hesaplara yeterince yer vermediği görülmüştür. Özellikle sürdürülebilirliğe katkılarından dolayı yeşil alt yapı sistemlerinin giderek yaygınlaşması gerektiğinden (Hengen ve diğ., 2016) yeni yayınlanan yönetmelikte daha fazla bu konuya yer verilerek ülkemizdeki sürdürülebilir sistemlerin uygulamalarının yaygınlaştırılması desteklenmelidir.

Sonuç olarak; su kaynaklarımızdan daha verimli şekilde yararlanmak ve mevcut kaynakları korumak için yeşil altyapı sistemleri uygulanmalıdır. Bu sistemlerin yaygınlaştırılması devlet politikası haline getirilmelidir. 


\section{Kaynaklar}

Auckland Regional Council (ARC). (1992). Stormwater Treatment Devices Design Guideline Manual. Technical Publication (10).

California Stormwater Quality Association. (2003).Stormwater Best Management Practice (BMP) Handbook: New Development and Redevelopment, Section Vegetated Swale.

Center for Watershed Protection (CWP).(1998). Better Site Design: A Handbook for Changing Development Rules in Your Community. Ellicott City, Maryland.

Claytor, R.A. Schueler, T.R. (1996). Design of Stormwater Filtering Systems. Center for Watershed Protection and Chesapeake Research Consortium, Ellicott, USA.

ConnDOT Drainage Manual. (2000).Storage Facilities Chapter 10: Outlet Hydraulics.

Çevre ve Şehircilik Bakanlı̆̆ı. (2017). Yağmur Suyu Toplama, Depolama ve Deşarj Sistemleri Hakkında Yönetmelik. Resmi Gazete. Sayı: 30105.

Department of Natural Resources and Water (2007). Queenslad Urban Drainage Manual (QUDM). Vol(1), Brisbane, Australia.

Department of Planning and Local Government. (2010).Water Sensitive Urban Design (WSUD) Technical Manual for the Greater Adelaide Region. Adelaide, South Australia.

Meteoroloji Genel Müdürlüğü (MGM). Göztepe Meteoroloji İstasyonu Yağış Şiddeti-Süre-Tekerrür Eğrileri.

Flanagan, K., Branchu, P., Ramier, D. \& Gromaire, M. C. (2017). Evaluation of The Relative Roles of A Vegetative Filter Strip and a Biofiltration Swale in A Treatment Train for Road Runoff. Water Science and Technology, 75, 987-997.

Healty Waterways Partnership.(2006). Water Sensitive Urban Design (WSUD) Technical Design Guidelines for South East Queensland.

Hengen, T. J., Sieverdıng, H. L. ve Stone, J. J. (2016). Lifecycle Assessment Analysis of Engineered Stormwater Control Methods Common to Urban Watersheds. Journal of Water Resources Planning and Management, 142.

Metropolitan Council \& Barr Engineering Company. (2001a). Minnesota Urban Small Sites Best Management Practice (BMP) Manual: Stormwater Best management Practices for Cold Climates. Section Constructed Wetlads:Wet Swales. Minneapolis, St. Paul, USA.

Metropolitan Council \& Barr Engineering Company. (2001b). Minnesota Urban Small Sites Best Management Practice (BMP) Manual: Stormwater Best management Practices for Cold Climates. Section Detention Systems: Dry Swales. Minneapolis, St. Paul, USA.

Minnesota Pollution Control Agency (MPCA). (2000). Protecting Water Quality in Urban Areas: Best Management Practices for Dealing with Storm Water Runoff from Urban, Suburban and Developing Areas of Minnesota. Minneapolis, USA.

Rahman, K. \& Weber, T. (2003). Sustainable Urban Development in Brisbane City - The Holy Grail? Water Science and Technology, 47, 73-79.

Revitt, D. M., Ellis, J. B. \& Lundy, L. (2017). Assessing The Impact of Swales on Receiving Water Quality. Urban Water Journal, 14, 839.

Southeastern Wisconsin Regional Planning Comission (SEWRPC). (1991).Cost of Urban Nonpoint Source Water Pollution Control Measures.Waukesha, USA, Technical Report(31).

Upper Parramatta River Catchment Trust. (2004). Water Sensitive Urban Design (WSUD), Technical Guidelines for Western Sydney.

URL-1: www.dsi.gov.tr (Erişim Tarihi: 03 Haziran 2017).

URL-2: http://www.degora.com/pdf/gpwat09tr.pdf (Erişim Tarihi: 03 Haziran 2017).

URL-3: Marrnaric.org/marmaricte-permakultur-uygulamalar1/yağmur-hendeği-ve-gölet/ (Erişim Tarihi: 03 Haziran2017).

URL-4: https://www.researchgate.net/publication/27458387(Erişim Tarihi: 28 May1s 2017).

Waterway Solutions Consulting Engineers. (2008). Stormwater Management Report (SMR) for: Dixon Street Coolangatta. Section 6: Hydraulic. Water Quality \& Geotechnical Engineering.

Yao, R. (2013). Design and Management of Sustainable Built Environments. 129-130, London, Britain, Springer. 
EK 1. En kesit tiplerine göre yağmur hendeği parametrelerinin hesab1.

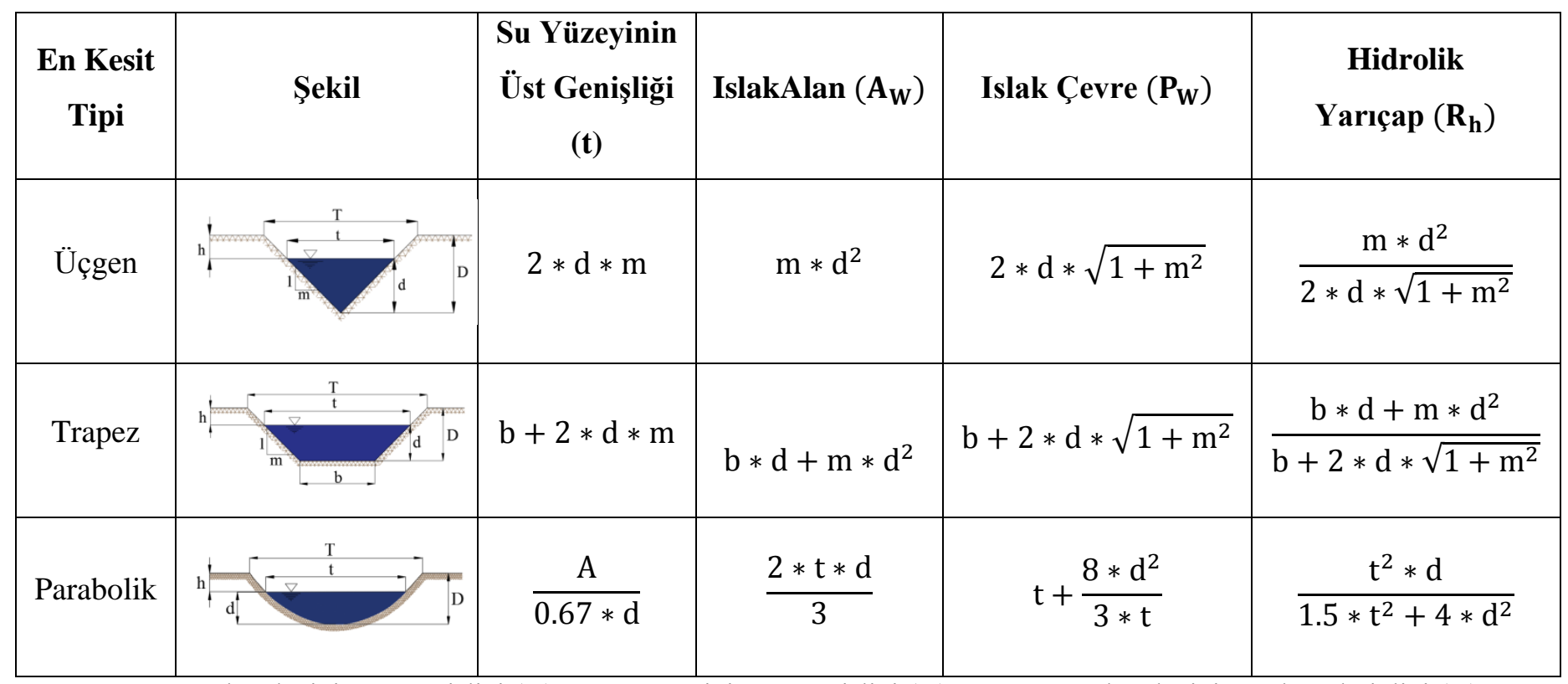

T: Yağmur hendeğinin üst genişliği (m), t: Su yüzeyinin üst genişliği (m), D: Yağmur hendeğinin toplam derinliği (m), d: Su derinliği (m), h: Hava payı (mm), m: Şev eğimi,b: Yağmur hendeğinin alt genişliği (m), A: En kesit alanı ( $\left.\mathrm{m}^{2}\right)$.

EK 2. Savak kret genişliği ve yüksekliğine bağlı olarak geniş kretli savak katsayısı $\left(\mathrm{C}_{\mathrm{w}}\right.$; CoonDot, 2000).

\begin{tabular}{|c|c|c|c|c|c|c|c|c|c|c|c|c|c|c|c|}
\hline \multirow{2}{*}{$\begin{array}{l}\text { Savak Yükü } \\
(\mathbf{m})\end{array}$} & \multicolumn{15}{|c|}{ Savak Kret Genişliği (m) } \\
\hline & 0.15 & 0.20 & $\mathbf{0 . 3 0}$ & 0.40 & 0.50 & 0.60 & 0.70 & $\mathbf{0 . 8 0}$ & $\mathbf{0 . 9 0}$ & 1.00 & 1.25 & 1.50 & 2.00 & 3.00 & 4.00 \\
\hline 0.10 & 1.59 & 1.56 & 1.50 & 1.47 & 1.45 & 1.43 & 1.42 & 1.41 & 1.40 & 1.39 & 1.37 & 1.35 & 1.36 & 1.40 & 1.45 \\
\hline 0.15 & 1.65 & 1.60 & 1.51 & 1.48 & 1.45 & 1.44 & 1.44 & 1.44 & 1.45 & 1.45 & 1.44 & 1.43 & 1.44 & 1.45 & 1.47 \\
\hline 0.20 & 1.73 & 1.66 & 1.54 & 1.49 & 1.46 & 1.44 & 1.44 & 1.45 & 1.47 & 1.48 & 1.48 & 1.49 & 1.49 & 1.49 & 1.48 \\
\hline 0.30 & 1.83 & 1.77 & 1.64 & 1.56 & 1.50 & 1.47 & 1.46 & 1.46 & 1.46 & 1.47 & 1.47 & 1.48 & 1.48 & 1.48 & 1.46 \\
\hline 0.40 & 1.83 & 1.80 & 1.74 & 1.65 & 1.57 & 1.52 & 1.49 & 1.47 & 1.46 & 1.46 & 1.47 & 1.47 & 1.47 & 1.48 & 1.47 \\
\hline & & 1.82 & & & & & & & & & & 1.46 & & 1.46 & 1.45 \\
\hline 0.60 & 1.83 & 1.83 & 1.82 & 1.73 & 1.65 & 1.58 & 1.54 & 1.46 & 1.31 & 1.34 & 1.48 & 1.46 & 1.46 & 1.46 & 1.45 \\
\hline 0.70 & 1.83 & 1.83 & 1.83 & 1.78 & 1.72 & 1.65 & 1.60 & 1.53 & 1.44 & 1.45 & 1.49 & 1.47 & 1.47 & 1.46 & 1.45 \\
\hline 0.80 & 1.83 & 1.83 & 1.83 & 1.82 & 1.79 & 1.72 & 1.66 & 1.60 & 1.57 & 1.55 & 1.50 & 1.47 & 1.47 & 1.46 & 1.45 \\
\hline 0.90 & 1.83 & 1.83 & 1.83 & 1.83 & 1.81 & 1.76 & 1.71 & 1.66 & 1.61 & 1.58 & 1.50 & 1.47 & 1.47 & 1.46 & 1.45 \\
\hline 1.00 & 1.83 & 1.83 & 1.83 & 1.83 & 1.82 & 1.81 & 1.76 & 1.70 & 1.64 & 1.60 & 1.51 & 1.48 & 1.47 & 1.46 & 1.45 \\
\hline 1.10 & 1.83 & 1.83 & 1.83 & 1.83 & 1.83 & 1.83 & 1.80 & 1.75 & 1.66 & 1.62 & 1.52 & 1.49 & 1.47 & 1.46 & 1.45 \\
\hline 1.20 & 1.83 & 1.83 & 1.83 & 1.83 & 1.83 & 1.83 & 1.83 & 1.79 & 1.70 & 1.65 & 1.53 & 1.49 & 1.48 & 1.46 & 1.45 \\
\hline 1.30 & 1.83 & 1.83 & 1.83 & 1.83 & 1.83 & 1.83 & 1.83 & 1.82 & 1.77 & 1.71 & 1.56 & 1.51 & 1.49 & 1.46 & 1.45 \\
\hline 1.40 & 1.83 & 1.83 & 1.83 & 1.83 & 1.83 & 1.83 & 1.83 & 1.83 & 1.83 & 1.77 & 1.60 & 1.52 & 1.50 & 1.46 & 1.45 \\
\hline 1.50 & 1.83 & 1.83 & 1.83 & 1.83 & 1.83 & 1.83 & 1.83 & 1.83 & 1.83 & 1.79 & 1.66 & 1.55 & 1.51 & 1.46 & 1.45 \\
\hline 1.60 & 1.83 & 1.83 & 1.83 & 1.83 & 1.83 & 1.83 & 1.83 & 1.83 & 1.83 & 1.81 & 1.74 & 1.58 & 1.53 & 1.46 & 1.45 \\
\hline
\end{tabular}


EK 3. İstanbul ili Kadıköy ilçesi Göztepe meteoroloji istasyonu yağışs şiddeti-süre-tekerrür eğrileri (MGM).

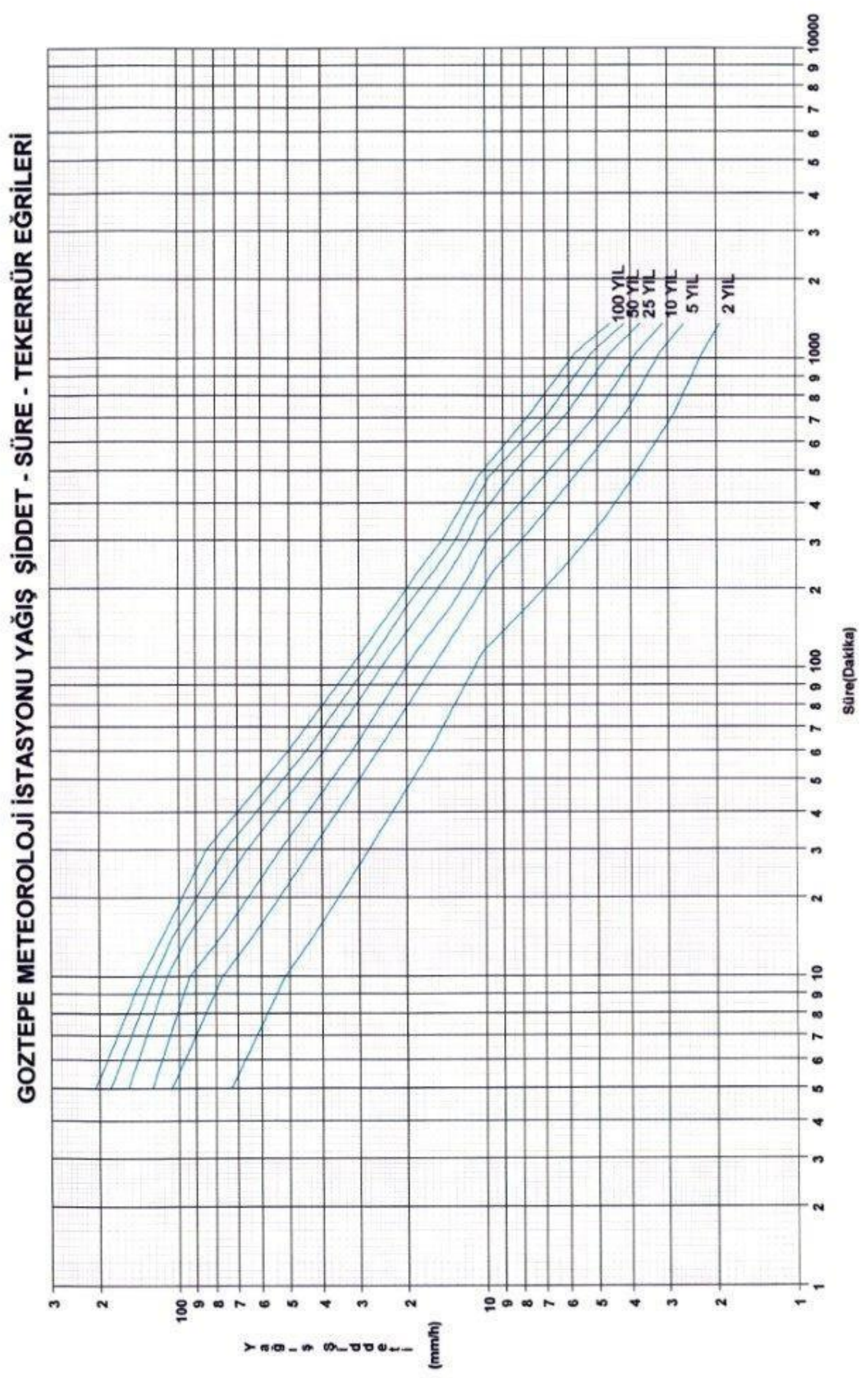


EK 4. 500 hektardan küçük havza alanları için varsayılan ortalama akarsu hızları (QUDM, 2007).

\begin{tabular}{lcc}
\multicolumn{1}{c}{ Arazi Tipi } & $\begin{array}{c}\text { Havza Yüzeyinin } \\
\text { Ortalama Eğimi (\%) }\end{array}$ & $\begin{array}{c}\text { Varsayılan } \\
\text { Ortalama Hızlar (m/s) }\end{array}$ \\
\hline Düz & $0-1.5$ & 0.3 \\
Dalgalı & $1.5-4.0$ & 0.7 \\
Dağlık & $4.0-8.0$ & 0.9 \\
Dik yokuş, uçurum & $8.0-15.0$ & 1.5 \\
Çok dik kayalık dağlar & $>15.0$ & 3.0 \\
\hline
\end{tabular}

EK 5. Giriş süresinin hesabı için diyagram (30105 Sayılı Yönetmelik).

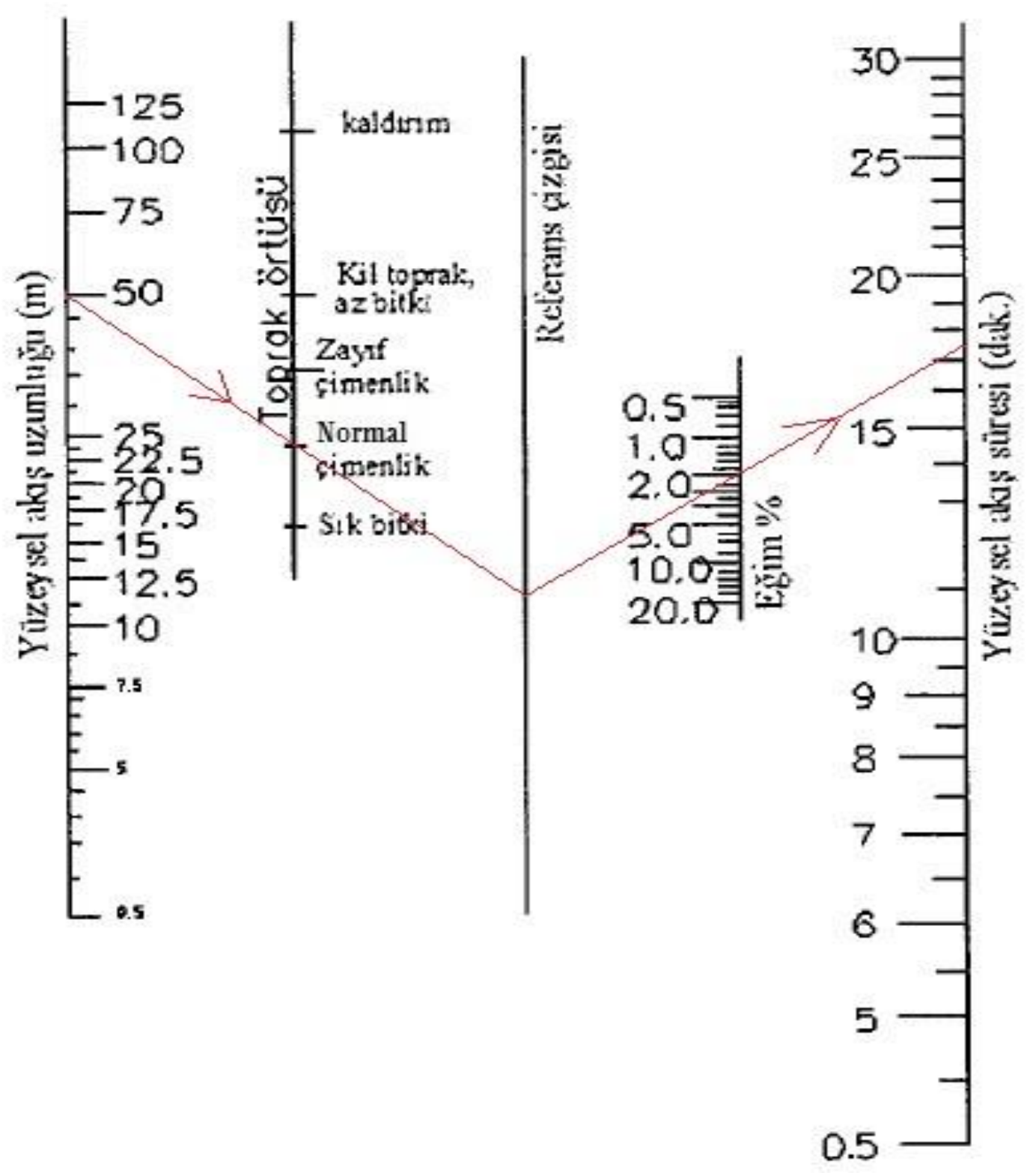

